\title{
Influence of the nitrided layer thickness of dies made of two types of tool steel used in hot extrusion of valve forgings made of nickel-chromium steel on the durability of these tools
}

\author{
Marek Hawryluk $^{1} \cdot$ Marzena Lachowicz $^{1} \cdot$ Marta Janik $^{2} \cdot$ Jacek Ziemba $^{1} \cdot$ Zbigniew Gronostajski $^{1}$
}

Received: 23 June 2021 / Revised: 18 August 2021 / Accepted: 5 September 2021 / Published online: 21 September 2021

(C) The Author(s) 2021

\begin{abstract}
The study constitutes an analysis of the durability of dies used in the first operation of producing valve forgings from chromium-nickel steel (NCF 3015) for motor trucks. The average durability of the dies (subjected to standard thermal treatment and nitriding) in this operation equals about 800 forgings. To perform an in-depth analysis of the effect of the nitrided layer thickness $(0.1 \mathrm{~mm}$ and $0.2 \mathrm{~mm}$ ) and the tool material (W360 and QRO90) on the possibilities of increasing the die durability, complex studies were carried out, which included: a macroscopic analysis combined with 3D scanning, microstructural examinations using a scanning microscope and a metallographic microscope, as well as hardness measurements. A minimum of three tools were tested for different variants, and for each of them, one representative die was selected for detailed examinations. The research showed the presence of abrasive wear, thermo-mechanical fatigue and traces of adhesive wear as well as plastic deformation on the surface of the working impressions. Also observed was the effect of the extruded material sticking to the tools (high friction and the presence of intermetallic phases in the extruded material) and the forging being blocked in the smallest section of the die, which is a critical factor causing a production shutdown and the necessity of tool replacement. The highest mean durability equalling 2600 forgings was obtained for the dies with a lower carbon content and a higher content of vanadium and the nitrided layer thickness at the level of $0.2 \mathrm{~mm}$. The lowest mean durability (after one forging item) was recorded for the dies made of steel with a higher carbon content and a higher chromium content, forming less stable compound carbides and the thickness layer at the level of $0.1 \mathrm{~mm}$.
\end{abstract}

Keywords Engine valve forging $\cdot$ Nitrided layer thickness $\cdot$ Forging tool durability $\cdot$ Chromium-nickel steel $\cdot$ Wear . Destructive mechanisms

Marek Hawryluk

marek.hawryluk@pwr.edu.pl

Marzena Lachowicz

marzena.lachowicz@pwr.edu.pl

Marta Janik

marta.janik@mahle.com

Jacek Ziemba

jacek.ziemba@pwr.edu.pl

Zbigniew Gronostajski

zbigniew.gronostajski@pwr.edu.pl

1 Department of Metal Forming, Welding and Metrology, Wrocław University of Science and Technology, 5

Łukasiewicza Str, 50-371 Wrocław, Poland

2 Valves Extrusion, Mahle Polska, Krotoszyn, Poland

\section{Introduction}

The valves used in motor truck engines usually operate at the temperatures $700-850{ }^{\circ} \mathrm{C}$. High pressure causes the valves (both suction and exhaust) to be subjected to cyclic thermal and mechanical loads [1-3]. Engine valves are usually made in hot extrusion and forging processes from high nickel austenitic steels or nickel superalloy (about $80 \% \mathrm{Ni}$ content) as well as chromium-nickel steels [4]. In the case of the technology of producing valves from chromium-nickel steel (through forging with pre-extrusion), the obtained items are characterized by better mechanical properties and surface quality. This technology is, unfortunately, rarely applied, as it is a forging process realized in closed dies, very difficult to master, which requires preparation of the preform's weight with the accuracy of up to $1 \%$, as well as ensuring the appropriate (in a narrow scope) heating temperature of the 
charge and designing proper shapes of the die impressions, so that they can be well filled. However, the biggest problem is constituted by the high pressures, intensive friction and cyclic temperature changes, which cause varying and difficult tribological conditions. For this reason, problems with low die durability occur (in extreme cases, even a dozen or so forgings) and faulty products are formed, resulting from the difficulties in shaping steel with a high content of nickel and selecting the optimal process parameters. This results from the increased adhesion of the charge material, i.e. nickel-chromium steel ( $\mathrm{Ni} 25-35 \%$ and $\mathrm{Cr} 15-20 \%$ ) to the tool substrate made of tool steel during hot co-extrusion, in the forging process. An effect of such conditions as well as a result of high path of friction is that the extruded material becomes blocked or jammed in the eye of the die [5]. The presence of intermetallic phases in microstructure makes the forging process more difficult, which reduces the deformability, and their hard particles lead to rapid tool wear [6-8]. Low durability of tools made of tool steels for hot operations is the main problem in the case of forming forgings from austenitic steels. This currently constitutes a big and still unsolved problem, which is a significant challenge for scientists from the field of material sciences as well as technologists of the production processes, including die forging [9]. It is crucial to select the appropriate technological parameters, such as tribological conditions, including lubrication, optimal shape of the forming tools ensuring reduced forming forces, and also minimized residual deformations. Figure 1 shows the mean tool durability during the forging of different steels for the same forged element.

In the case of upsetting of stainless steel type 304 (18\% $\mathrm{Ni}$ and $10 \% \mathrm{Cr}$ ), the durability was lower than one-fifth of the durability of the die used for the upsetting of low carbon steel and lower than one-third for the upsetting of steel 4340 ( $2 \% \mathrm{Ni}$ and \% Cr). The presented process refers to forging with a flash, which additionally shows how difficult it is to

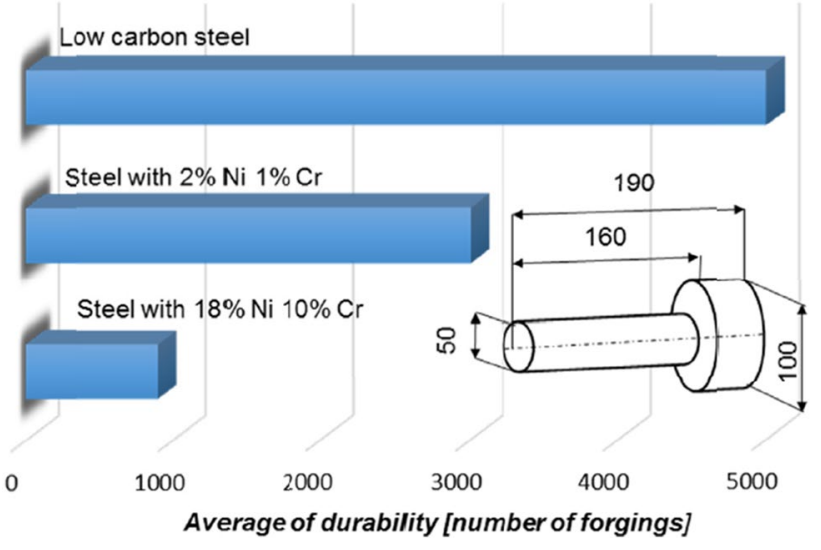

Fig. 1 Comparison of forging tool durability during the forging of the same element made of different steels [10] design the process of forging a valve in closed dies, where the pressures are many times higher [10].

In typical hot die forging processes, the tools are subjected to a simultaneous operation of many factors causing their destruction, which mainly include cyclic intensive thermal shocks ( 80 to over $1000{ }^{\circ} \mathrm{C}$ ) and cyclic varying mechanical loads (0 to over $1500 \mathrm{MPa}$ ) as well as high friction [11]. It should also be emphasized that die forging is a dynamic process, where the material deformation itself usually lasts as little as $0.2 \mathrm{~s}$. For this reason, the operation of these factors is mainly exerted onto the surface layer of the tool (as a result of intensive flow of the deformed material on the working surface of the tools), and so modification of the forging tool surface layer seems one of the most effective methods of increasing their durability [12]. The authors of the work [13] indicate that it is necessary to optimize the nitriding process, commonly used for this purpose, whose parameters influence the final microstructure and properties of the surface layer. At the same time, they indicate that the search for methods of combining the nitriding process with other surface engineering technologies may also be a necessity in this respect. A preferred technology is combining the nitriding process with deposition of hard coatings of anti-wear character by PVD methods. The author has shown in his work [14] that in the case of the application of a composite layers nitrided layer/ $\mathrm{CrN}$, a greater thickness of the $\mathrm{CrN}$ coating effectively reduces the tempering effect of heat on the die material. The use of composite PVD coatings also makes it possible to obtain a surface layer with a microstructure consisting of nitrides of complex chemical composition [15]. Despite the progress in the field of many different surface engineering methods, currently, the most popular and best-mastered, low-cost method of increasing forging tool durability is still thermo-chemical treatment through nitriding (plasma nitriding, plasma diffusion treatment and gas nitriding), which, however, does not always provide a clear effect of durability improvement [16, 17]. Nitriding is a procedure consisting in diffusive saturation of the tool's surface layer with nitrogen. The nitrides formed in the diffusive layer increase material hardness, thus increasing its resistance to abrasive wear and corrosion as well as fatigue strength $[18,19]$. The analysis of the possibilities of improving the durability of forging tools through nitriding has shown that this method makes it possible to increase their durability even multiple times [20,21]. Due to the fact that nitriding does not include austenitization or rapid cooling, for martensite to form, the process ensures minimization of deformations and high control and precision of the tool's dimensions after the process. It turns out, however, that despite the gas nitriding technology having been commonly used in industry for a long time, unfortunately it is often carried out on devices which make the nitriding parameter control difficult $[22,23]$. The low effects provided by the applied nitriding processes result from the fact that elements of different sizes and made of different 
materials are often treated in one universal process. Is very difficult to obtain the desired structure of the nitrided layer, which can have a determining effect on the tool's durability. The research of the authors [24] proves that an important role in this scope is also played by the type of alloying elements present in steel. The conducted investigations have shown that the effectiveness in improving forging tool durability largely depends on the structure and profile and to a lesser extent on the thickness of the obtained nitrided layer [25]. However, obtaining a high thickness of the nitrided layer for forging tools, reaching over $0.3 \mathrm{~mm}$, is difficult with the consideration of effective hardness, as well as uneconomical, as it significantly prolongs the process. Despite many studies and analyses performed so far, the application of thermo-chemical treatment consisting in nitriding is still a current research field. The reason for it is that, as it turns out, for each forging tool and process, individual parameters of such a treatment should be selected because only such can ensure increase of the durability of forging tools and instrumentation [26-31]. The use of hybrid coatings allows the fatigue strength to be improved by up to $80 \%$ [26]. The authors of the work [27], after depositing complex AlCrSiN-based coatings, managed to obtain an improvement in fatigue resistance both at room temperature and elevated temperature. However, the final influence on the obtained properties is exerted by the type of PVD coating deposited after nitriding, as well as the condition of the surface [28]. The authors of the work [29] showed that the appropriate selection of plasma nitriding parameters can significantly contribute to the improvement of corrosion resistance of tool steel. The authors associate this with the diversity of the chemical composition and microstructure of the obtained nitrided layers. The authors of the work [30] indicate that the optimal properties defined by surface hardness, hardness of the secondary tempering material and wear resistance are obtained during plasma nitriding at $500^{\circ}$. The authors of the work [31] suggest that the optimal temperature for obtaining maximum hardness is about $515{ }^{\circ} \mathrm{C}$. This is attributed to the increase in stress in the crystallographic lattice of the nitrides formed.

That is why it is justifiable to conduct advanced complex studies analysing the destructive phenomena and mechanisms.This, in turn, will make it possible to reduce the unit production costs of valve type forgings as well as other elements manufactured in die forging processes from austenitic high nickel steels, for which the mean durability is much lower than that for carbon steels $[32,33]$.

\section{Materials and methods}

A detailed analysis was performed on dies used in the first (Ist) operation of hot co-extrusion of a long shank tipped with a preliminarily formed element called "bulb" (Fig. 2c). Figure 2a shows a CAD model together with the arrangement of areas on the tool section surface, for better orientation and analysis of results. In turn, Fig. $2 \mathrm{~b}$ presents an image of one-half of an out-of-service die compiled with a surface analysis scan.

The dies were made of tool steel for hot operations grade QRO90 and W360, subjected to standard thermal treatment for each steel grade (quenching and two times tempering, according to the operation sheet), followed by gas nitriding at $500{ }^{\circ} \mathrm{C}$ in a NITREX furnace in an ammonia atmosphere, for tools with a nitride layer thickness of $0.1 \mathrm{~mm}$ for $5 \mathrm{~h}$ and for tools with a nitride layer thickness of $25 \mathrm{~h}$. The surface of the ready tool impressions (after thermal and thermomechanical treatment as well as finishing mechanical treatment) should characterize the hardness at the level of about $1100 \mathrm{HV}$. The ready tools are heated to the working temperature of about $200{ }^{\circ} \mathrm{C}$ and then mounted in a press. The temperature of the charge material is $1040{ }^{\circ} \mathrm{C}$. During the extrusion process, the tools are lubricated and cooled with a lubricating-cooling agent based on graphite. The mean hardness of the dies equals about 800 items.

The technological parameters of the extrusion process was the same for every tool used in the study. The temperature of the input material was $1050-1060{ }^{\circ} \mathrm{C}$, the cycle time was $5.5 \mathrm{~s}$, the temperature of dies was $350{ }^{\circ} \mathrm{C}$, the friction factor was $\mu=0.3$, and the area reduction was $18 \%$.

A detailed analysis was performed on four dies (as representative tools for two different thicknesses of the nitrided layer), for which detailed information has been given in Table 1 . The HV values were given as the conversion value. In the tests, dies made of two tool steel grades for hot operations were used. The first group of tools for blocking dies was made of steel W360 in two variants of thermo-chemical treatment: hardening and tempering to obtain hardness 56HRC and nitriding to obtain thickness of 0.1 and $0.2 \mathrm{~mm}$, respectively. The second group of tools was made of steel QRO90, where the hardness of the applied tools equalled 53 HRC, while nitriding was carried out to obtain thicknesses of 0.1 and $0.2 \mathrm{~mm}$.

\subsection{To perform a complex analysis, the following research methods were applied}

- macroscopic tests combined with a measurement of the wear/excess degree on the tool working surface through scanning by means of a measuring arm ROMER Absolute ARM 7520si integrated with a scanner RS3 as well as a comparison of the scan geometry with the CAD models;

- microstructure examinations in the surface layer in tool cross section conducted by means of Leica model DM6000M; tools after preparation of samples and metallographic microsections-etching with 5\% nital (grinding and polishing on a grinding-polishing machine, Stuers350); 
(a)

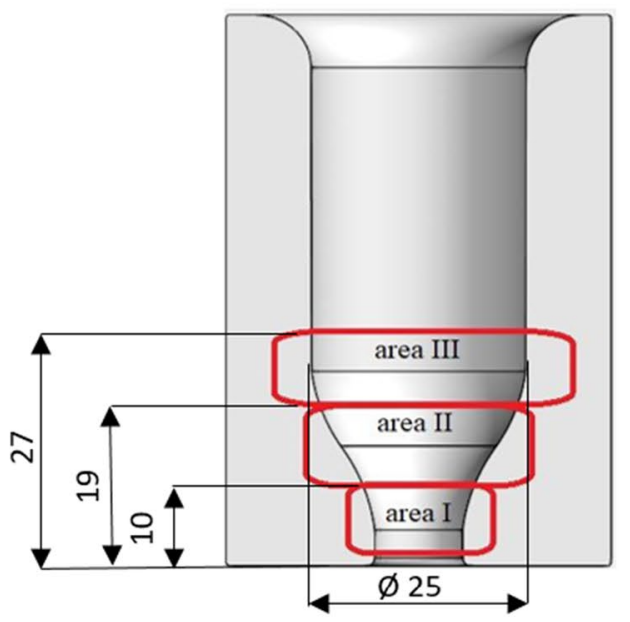

(b)

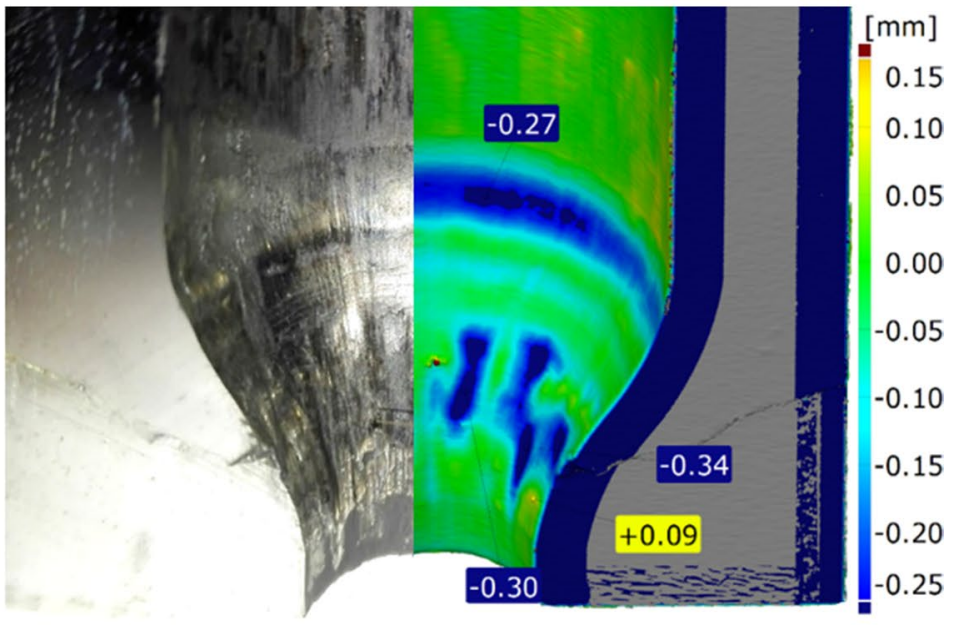

(c)
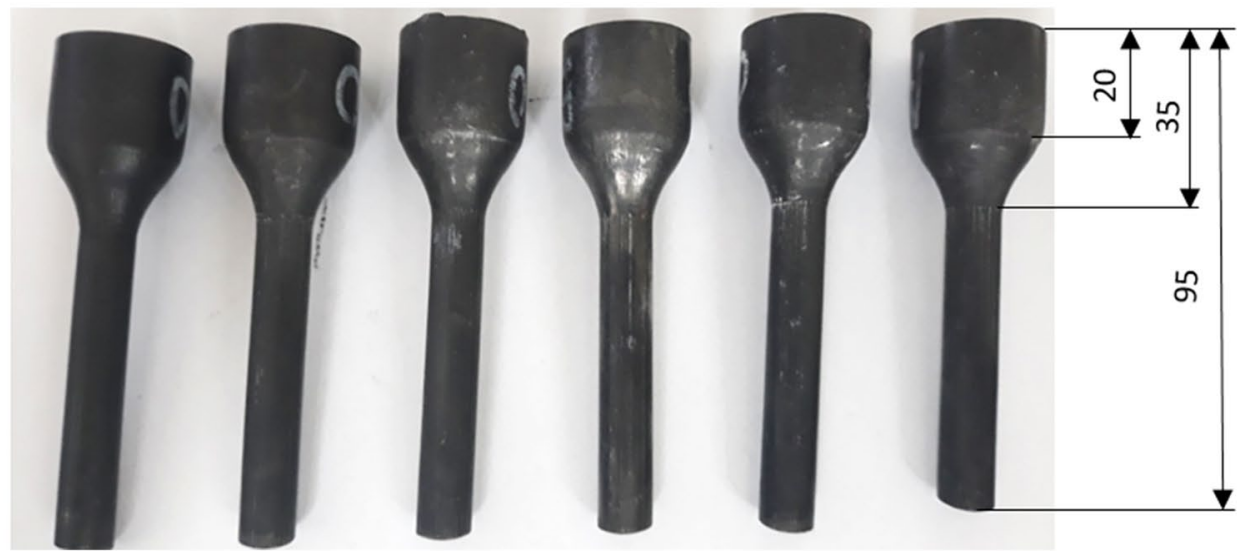

Fig. 2 View of a tool section: (a) CAD model with marked selected measurement areas, (b) exemplary image of one-half of a die compiled with the scanning results, (c) exemplary images of consecutive forgings after the first (Ist) operation

Table 1 Compilation of tools used in the studies

\begin{tabular}{lllll}
\hline Symbol & $\begin{array}{l}\text { Steel for block- } \\
\text { ing die }\end{array}$ & $\begin{array}{l}\text { Blocking die hardness of core } \\
\text { material [HRC/HV] }\end{array}$ & $\begin{array}{l}\text { Nitrided layer } \\
\text { thickness [mm] }\end{array}$ & $\begin{array}{l}\text { Mean number of } \\
\text { forgings made by } \\
\text { the tool }\end{array}$ \\
\hline W1 & W360 & $56 / 615$ & 0,1 & 1 \\
W2 & QRO90 & $53 / 560$ & 0,1 & 1260 \\
W3 & W360 & $56 / 615$ & 0,2 & 1830 \\
W4 & QRO90 & $53 / 560$ & 0,2 & 2600 \\
\hline
\end{tabular}

- a chemical composition analysis carried out with the use of glow discharge optical emission spectroscopy (GDOES) by means of an analyser GDS 500A by LECO;

- observations of the destruction features on the working surface with the use of a scanning microscope Phenom ProX coupled with an EDX detector;
- a microhardnesss measurement in the cross section in the function of the distance from the surface by means of a hardness tester LECO LC100 performed to evaluate the degradation taking place in the tool surface area caused by the operation of high temperature during forging. 


\section{Results and discussion}

\subsection{Macroscopic analysis combined with geometrical changes of tool working impressions by means of 3D scanning}

Figure 3 shows the macro-images as well as scanning results for the representative tools. All the tools were removed from the process after reaching the maximal number of produced forgings, which means that further production would have led to producing forgings that did not fulfil the quality requirements. In the analysis of both the macro-images of the cross- sections of the cut dies and the scans presented in Fig. 3, we can point to a few characteristic areas with different amounts and sizes of wear and loss. It should be emphasized that the areas which form the forging and have an effect on its possible defects, which determine the removal of the tools, are basically areas no. I, II and III, shown in Fig. 2a.

For this reason, those were the areas subjected to a microscopic analysis and hardness measurements in further investigations. However, in the upper cylindrical part of the tools, we can observe traces of tool wear, or sticking of the charge material or graphite, and these defects are oriented rather vertically and non-symmetrically.

It should be noted that the macro-results as well as the scans can slightly differ, as all the representative dies were

(a)

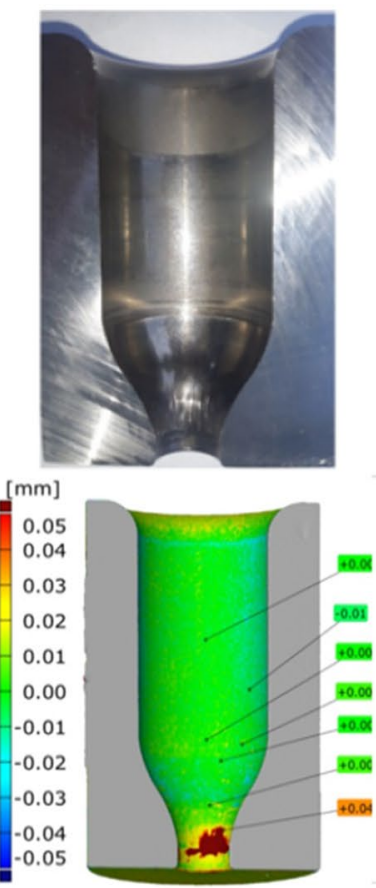

(b)
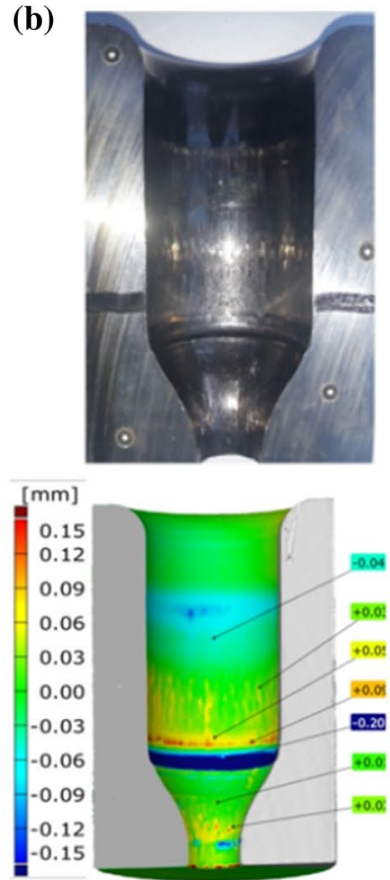

Fig. 3 Macro-images and geometrical changes results obtained by means of 3D scanning for the analysed tools: (a) W360, nitrided layer thickness $0.1 \mathrm{~mm}$ and after producing 1 forging, (b) QRO90, $0.1 \mathrm{~mm}$, (c)
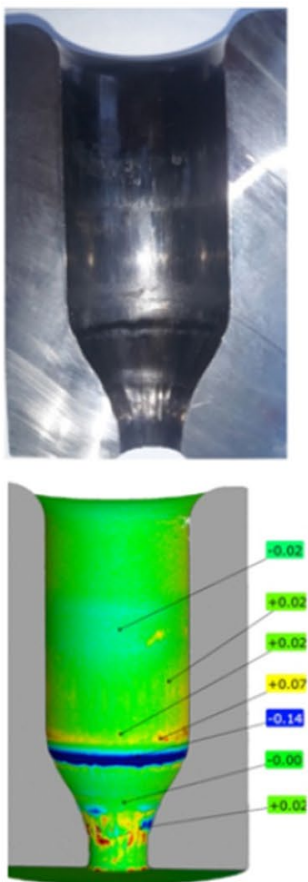

(d)
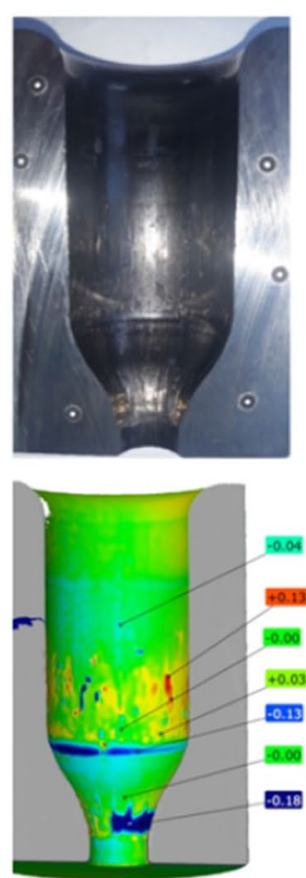

cut into halves and one of the halves was scanned, while the other used for micro-tests and hardness measurements. For all the tools, material loss or wear is observed in the area where the cylinder transitions into the cone (area no. III) as well as in the area of the smallest cross section, i.e. in the opening where the shank of the forging is shaped, that is in the vicinity of area no. I (Fig. 2a). The biggest loss at the level of over $0.05 \mathrm{~mm}$ in area no. I can be observed for tools made of steel QRO90, which, at the beginning of the process, had a nitrided layer at the level of $0.2 \mathrm{~mm}$ (Fig. 3d). In turn, for tools (W360), which, at the beginning of the process, had a nitrided layer at the level of $0.1 \mathrm{~mm}$, in this area (area no. I), we can notice material growth $(+0.04 \mathrm{~mm})$, resulting probably from the sticking of the forging material (for this variant, the tools were removed after 1 forging blocked in the impression). For the rest of the tools (variant W2 and W3), in area no. I, we can observe both loss and growth of material, which points to a possible occurrence of abrasive wear and plastic deformation as well as sticking of the forging material to the tool. For these tools, in area no. I, one can observe deviation values at the level of $-0.04 \mathrm{~mm}$, but also $+0.03 \mathrm{~mm}$. In turn, for area no. II, basically for all the tools, based on the scanning results, there are no visible traces of loss or growth of material. However, a deeper analysis of the macroscopic images reveals in this area traces of wear, yet their character (smoothed grooves or a gentle network of thermo-mechanical cracks) makes

1260 forgings, (c) W360, $0.2 \mathrm{~mm}, 1830$ forgings, (d) QRO90, $0.2 \mathrm{~mm}, 2600$ forgings 
such defects below the scanner's accuracy (that declared by supplierer accuracy of the scanning system in accordance with B89.4.22 equals $0.053 \mathrm{~mm}$ ). For the tools (W1, W2), which made a smaller number of forgings, we can observe, especially in the micro-images, wear in the so-called funnel, that is, in area no. II, whereby it is asymmetrical and characterized by longitudinal scratches and grooves on the circumferential surface. The biggest wear is observed in the area where the cross section of the cylinder transitions into the cone (area no. III from Fig. 2), whereby, in the case of tool W1, in this area, both in the macro-images and in the scan image, no visible traces of wear can be seen. For tool $\mathrm{W} 2$, in this area, a clear wider ring of wear can be noticed, and the material loss reaches over $0.1-0.2 \mathrm{~mm}$. In turn, for tools W3 and W4, the material loss values are similar, yet the width of the ring is much smaller.

Analysing the global results, we can see that the most worn tool is the die made of QRO90, with the layer thickness $0.2 \mathrm{~mm}, 2600$ forgings, for which the biggest wear is both in area no. I and III. In turn, for the tools which worked over only one forging and were then removed from production, only in area no. I can we see material growth which seems to be critical. For tools W2 and W3, the biggest traces of wear are visible in area no. III, while in area no. I, both loss and growth of material can be noticed.

\subsection{Microscopic evaluation of tool working surface wear}

Microscopic tests were performed on the internal surface of the examined tools, in the surface area. Detailed analyses were made in areas no. I, II and III, shown in Fig. 2a.

\subsubsection{Analysis of the chemical composition of the examined dies}

In the first place, examinations related to a chemical composition analysis were conducted for each of the representative tools. Table 2 presents the results of the chemical composition analysis for the tested tools made by the spectrometric method; the chemical composition of this steel is not normalized and it is in accordance with that declared by the steel's producer.

In terms of chemical composition, the W1 and W3 tools are the closest to the $\mathrm{X} 38 \mathrm{CrMoV} 5-3$ grade in accordance with the EN ISO 4957 standard. Taking into account the content of the main alloying elements, i.e. $\mathrm{Cr}$, Mo and V, it contains a slightly lower content of chromium than steel of the grade $\mathrm{X} 38 \mathrm{CrMnV5-3}$. It is also characterized by a higher carbon content. Slight differences also apply to the content of silicon and manganese, which should be in the range from 0.3 to $0.5 \mathrm{wt} \%$. The steel used for the production of W2 and W4 tools in terms of chemical composition is the closest to the steel of the $32 \mathrm{CrMoV} 12-28$ grade. The content of chromium and molybdenum for this steel also contains a higher carbon, vanadium and silicon content than the normalized one. Steels used steels for forging dies are characterized by high metallurgical purity, as evidenced by the low content of sulphur and phosphorus.

Steel QRO90 characterizes in a lower carbon content than that of grade W360, which ensures its better ductility and thermal fatigue strength. A higher manganese content in steel QRO90 also favours its better impact strength. This steel has a higher content of vanadium, which is a strongly carbide-forming element, creating simple MC type carbides with high hardness and stability at high temperatures, contributing to an increased effect of secondary hardness. For this reason, steel QRO90 should be characterized by a higher tempering resistance than grade W360. The molybdenum content, which also hinders the processes occurring during tempering as well as secondary hardness, is slightly higher in steel grade W360. There is a significant difference between the two grades in the chromium content, which is lower in steel QRO90. A higher chromium content favours precipitation of compound carbides, mainly type $\mathrm{M}_{23} \mathrm{C}_{6}$, in steel W360, with a lower temperature stability, which more easily undergoes coalescence at elevated temperatures. The demonstrated chemical composition differences in both materials can be significant in the aspect of die wear.

Table 2 Chemical composition of the examined tool material in $\%$ of wt

\begin{tabular}{|c|c|c|c|c|c|c|c|c|c|c|c|c|c|}
\hline & $\begin{array}{l}\mathrm{C} \\
(\% \mathrm{wt})\end{array}$ & Mn (\%wt) & $\mathrm{Si}(\% \mathrm{wt})$ & $\begin{array}{l}\mathrm{P} \\
(\% \mathrm{wt})\end{array}$ & $\begin{array}{l}\mathrm{S} \\
(\% \mathrm{wt})\end{array}$ & $\mathrm{Cr}(\% \mathrm{w})$ & Mo (\%wt & $\begin{array}{l}\mathrm{V} \\
(\% \mathrm{wt})\end{array}$ & Ni (\%wt) & $\mathrm{Cu}(\% \mathrm{wt})$ & $\mathrm{Nb}$ (\%wt) & $\mathrm{Al}(\% \mathrm{wt})$ & $\mathrm{Fe}$ \\
\hline W1 & 0.504 & 0.216 & 0.258 & 0.006 & 0.001 & 4.63 & 2.89 & 0.580 & 0.085 & 0.043 & 0.018 & 0.011 & \\
\hline W2 & 0.382 & 0.797 & 0.347 & 0.006 & 0.001 & 2.81 & 2.29 & 0.853 & 0.073 & 0.111 & 0.028 & 0.016 & \\
\hline W3 & 0.504 & 0.218 & 0.258 & 0.006 & 0.001 & 4.86 & 2.88 & 0.578 & 0.085 & 0.043 & 0.018 & 0.011 & \\
\hline W4 & 0.364 & 0.785 & 0.356 & 0.006 & 0.002 & 2.79 & 2.26 & 0.842 & 0.073 & 0.109 & 0.030 & 0.019 & \\
\hline
\end{tabular}




\subsubsection{Microscopic observations in area I}

The results of the observations performed in area no. I are shown in Figs. 4, 5, 6 and 7. The tool material during the operation undergoes cyclic heating to over $600{ }^{\circ} \mathrm{C}$, and next, as a result of lubrication, it is cooled down to about $100{ }^{\circ} \mathrm{C}$ on the impression's surface [34]. The microstructure of die W1 did not show significant microstructural changes in the area of the light microscope. The area of critical wear disqualifying the tool from further work was in the biggest narrowing, where the valve die shank is shaped and the friction is high as a result of intensive material flow in this zone. In this area, sticking of the material from the forging with high thickness, localized in the lower section of this zone, was observed (Fig. 4a). A probable cause of this could have been underheating of the charge material and incomplete dissolution of hard intermetallic phases, which, with increased friction and higher plastic resistance in this area, could have led to blocking of the die, and thus damaging of the tools from group W1. These observations are in agreement with the scans shown in Fig. 3a, in which, in this area, material growth was observed. The insert made from this material but with a higher thickness (W3), after working over 1830 cycles, was characterized by numerous cracks, initiated
Fig. 4 Microstructure of the material on the longitudinal section of the die in area I: (a) W360, $0.1 \mathrm{~mm}, 1$ forging (W1) (b) W360, $0.2 \mathrm{~mm}, 1830$ forgings (W3), LM, etched (a)

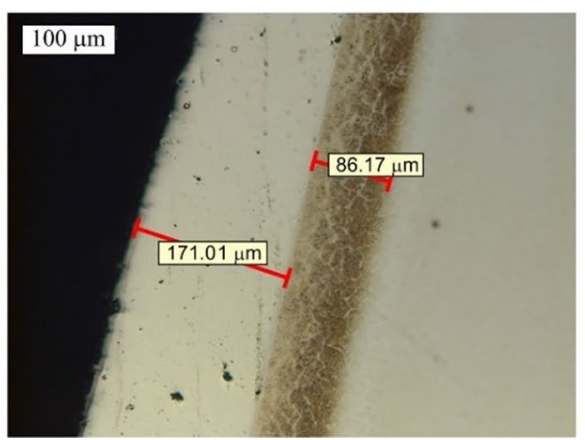

(b)

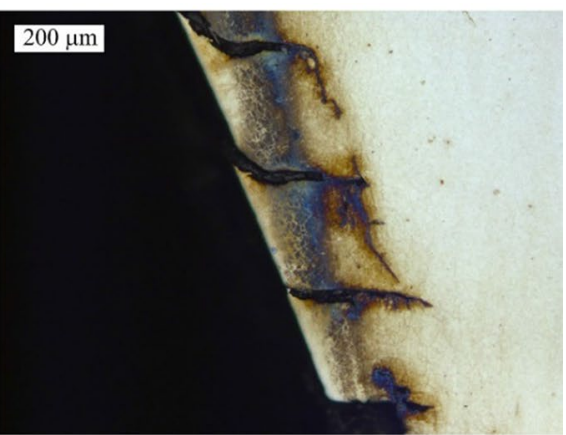

(a)

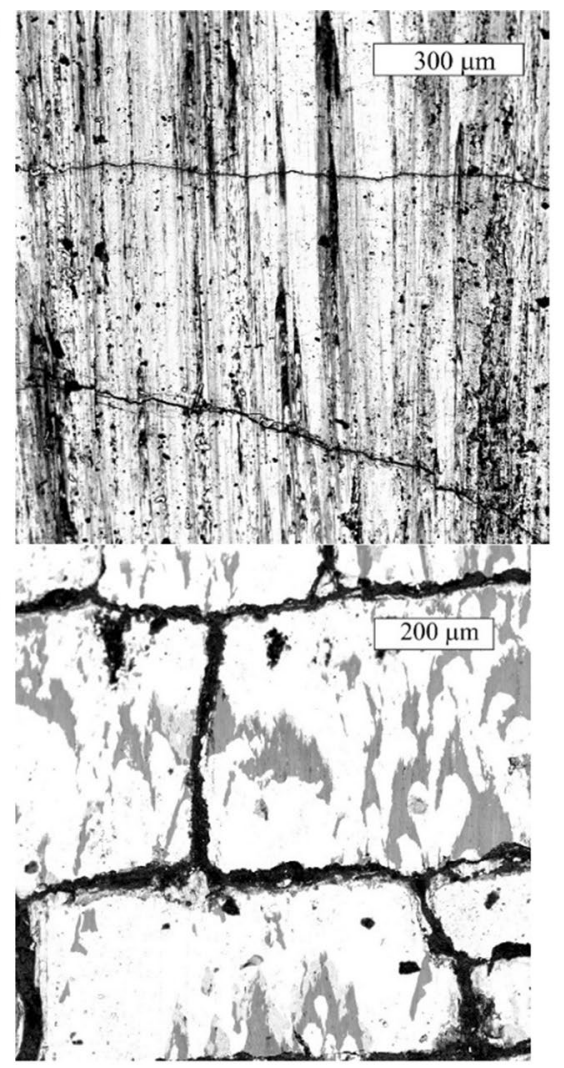

(b)

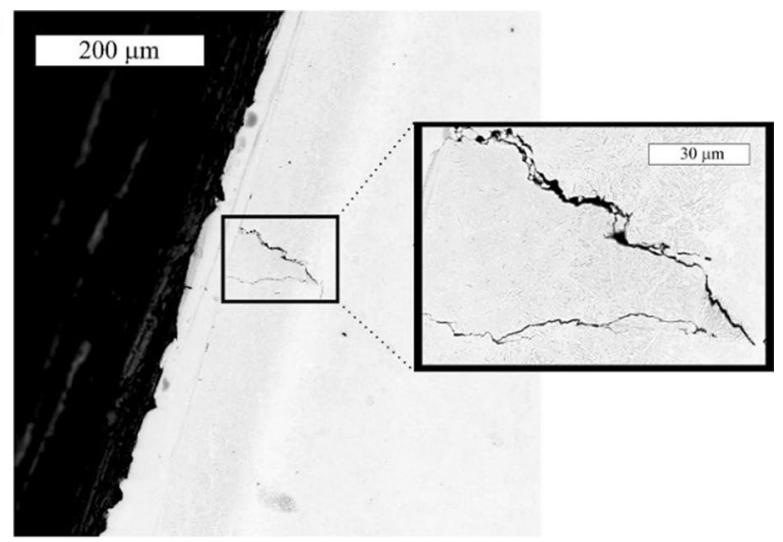

(d)

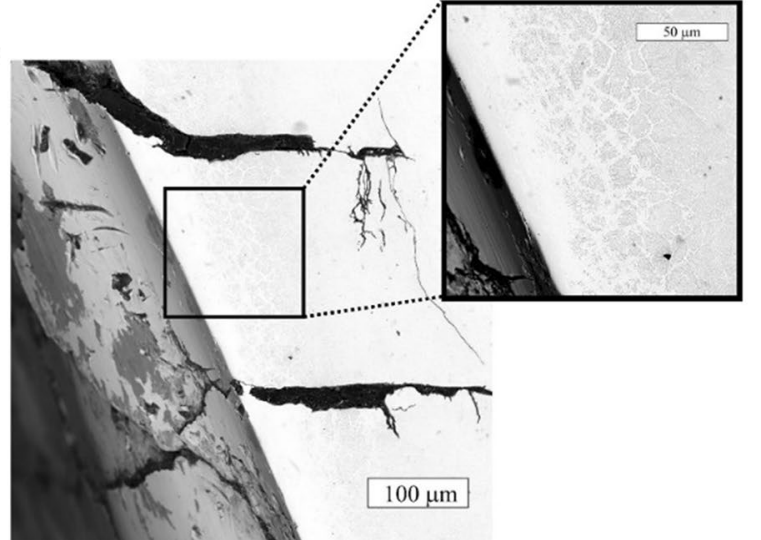

Fig. 5 Microscopic SEM areas obtained in area no. I: a, b) W360, $0.1 \mathrm{~mm}, 1$ forging (W1), c, d) W3 60, $0.2 \mathrm{~mm}, 1830$ forgings (W3) 
Fig. 6 Material microstructure on the die's longitudinal section in area no. I: (a) QRO90, $0.1 \mathrm{~mm}, 1260$ forgings (W2), (b) QRO90, $0.2 \mathrm{~mm}, 2600$ forgings (W4).LM, etched (a)

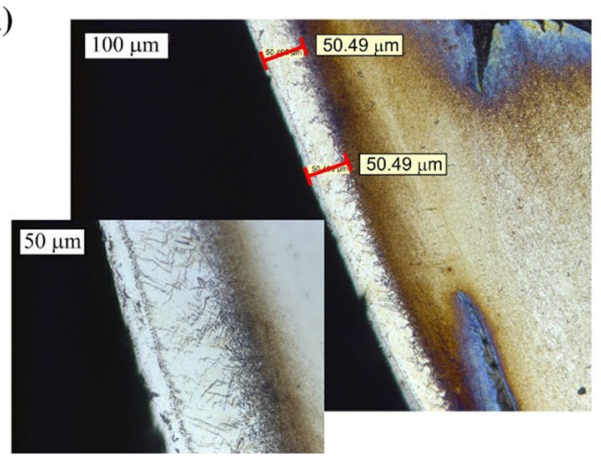

(a)

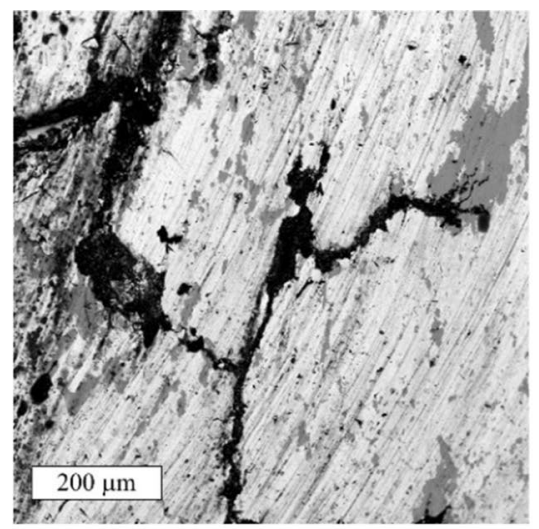

(c)

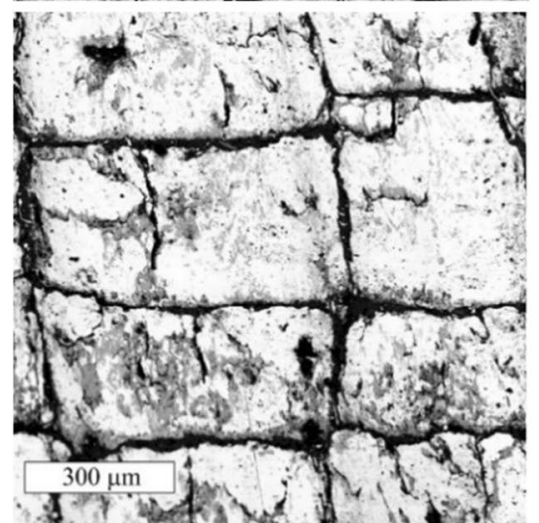

(b)

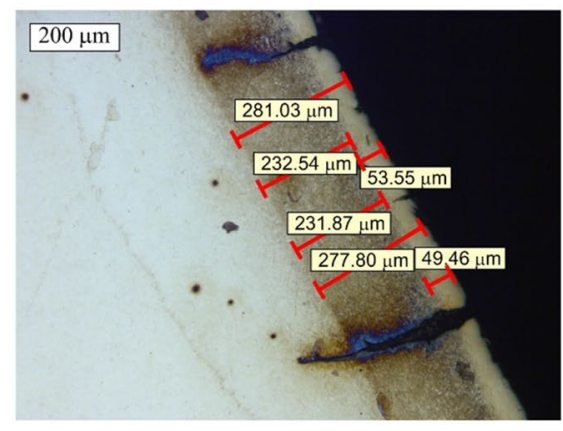

(b)

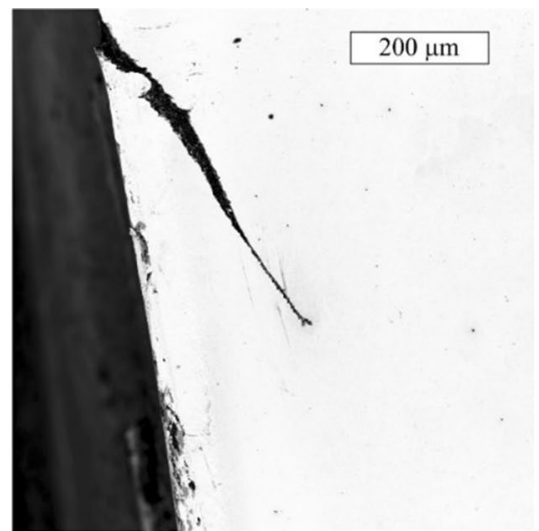

(d)

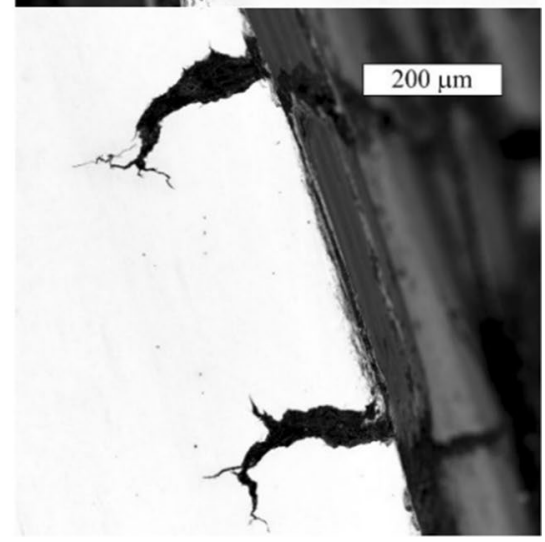

at the surface. The cracks were radial and formed whole groups of fatigue cracks (Fig. 4b, 5c,d), referred to as "erosion grooves" [35]. Deep cracks nucleate first, which enables their further growth. This makes it possible to decrease the expanding thermal stresses and delay the nucleation of other cracks, thus increasing the durability of the tool [36]. The microstructural changes observed in this area point to strong degradation of the die material. The literature data show that the decomposition of the nitrided layer is accompanied by denitriding [37]. The authors of the work [38] demonstrate that the denitriding process is accompanied by penetration of nitrogen into the material. The denitriding process can also be connected with the formation of diversified phases, for which nitrogen is used [39]. Die W1 with the nitrided layer thickness $0,1 \mathrm{~mm}$ was also characterized by cracks, which, however, did not form closed circuits but developed in a perpendicular way to the die axis and also had a smaller spacing (Fig. 5a,b). The cracks forming into the material developed perpendicular to the surface-initially transcrystalline, in the nitrided layer area, and then intercrystalline, on the prior-austenite grain boundaries (Fig. 5b).

In the case of dies W2 and W4, fatigue cracks were also observed, accompanied by the formation of a light-coloured area, (Fig. 6,7). The lowered hardness recorded in this area at the further stage of research excludes the formation of the so-called "white layer". The formation of such a layer is also attributed to decarburization by the authors of the study [35]. On the longitudinal section of tool W2, in the lower section of area no. I, the forging material sticking to the die impression with a non-homogeneous character was recorded 
(Fig. 6a, 8a). Taking into account the high temperatures in this area, which due to contact with the hot forging in the near-surface area may temporarily exceed the austenitizing temperatures, it should be expected that it may cause surface decarburization and decomposition of the nitrided layer. The decomposition of the nitrided layer will lead to the enrichment of the formed in the near-surface area austenite with nitrogen, which stabilizes it and decreas the martensitic transformation temperature $\mathrm{M}_{\mathrm{s}}$. Consequently, the next martensitic transformation caused by the high hardenability of the material could lead to the formation of martensite with a very large amount of residual austenite. This would explain the presence of single needles in this area. However, this issue requires further structural research.

In the case of die W2, the formed cracks had an irregular character. In the case of the inset made of steel QRO90 with a higher thickness of the nitrided layer (W4), the formed cracks were similar to those observed for insert W3, with a similar nitrided layer thickness, but made of steel W360. It should be noted that the thicker nitrided layer enabled the tool to work despite the presence of significant fatigue cracks in this area.

The non-homogeneity was confirmed by the EDS linear distribution of elements in this area, established by means of the EDS method, which demonstrated that the mottled area consists of refined fragments of scale and the charge material $(8 b, c)$.

After its detachment from the surface, the tools form oxide scales, which then become mixed with the charge material as a result of plastic deformation [39]. Barrau et al. [40] demonstrated that such mixing of oxide layers with the metal material is typical for temperatures of about $500{ }^{\circ} \mathrm{C}$. The presence of hard oxides in the area of interaction between the tool and the charge material will accelerate the wear of the tool [35]. The high tool work also favours the growth and removal of oxides from the tool. The element identification carried out in this area with the use of the EDS method shows that the scale, besides the oxygen, also contains elements capable of forming oxides, such as chromium, titanium or manganese. The high concentration of nickel identified in the remaining area, present basically mainly in the forging material (chromium-nickel steel), makes it possible to identify this area with this charge material (Fig. 9).

\subsubsection{Microscopic observations in area no. II}

In area no. II, for all the tools, surface changes were observed (Fig. 10, 11, 12, 13). In the case of die W1, the changes did not affect the character of the nitrided layer's microstructure. (Fig. 10a).

In the working surface, fine surface cracks were observed, which did not penetrate into the material. They were accompanied by plastic deformation leading to the formation of characteristic wrinkles on the tool surface $(11 a, b)$. Tool W3 made of steel W360 with the nitrided layer thickness $0.2 \mathrm{~mm}$ was characterized by the presence of perpendicular cracks initiated in the surface area, which formed a network of thermal fatigue cracks (Figs. 10b, 11c,d). The cracks formed

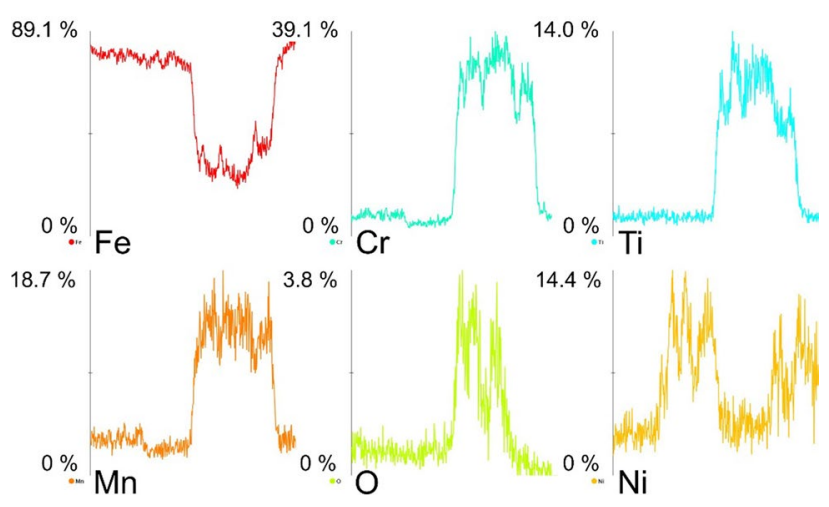

Fig. 9 EDS linear distributions of $\mathrm{Fe}, \mathrm{Cr}, \mathrm{Ti}, \mathrm{Mn}, \mathrm{O}$ and $\mathrm{Ni}$ obtained in the area pointed to in Fig. 8c (a)

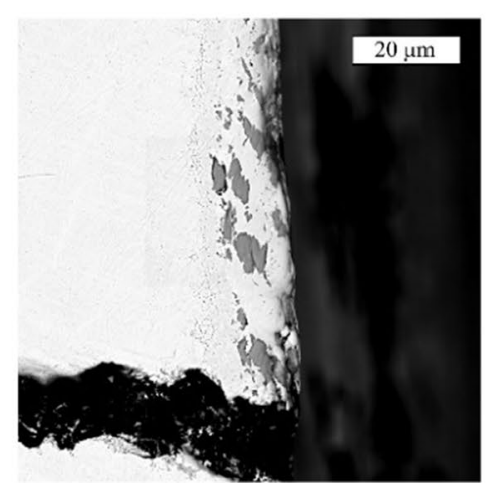

(b)

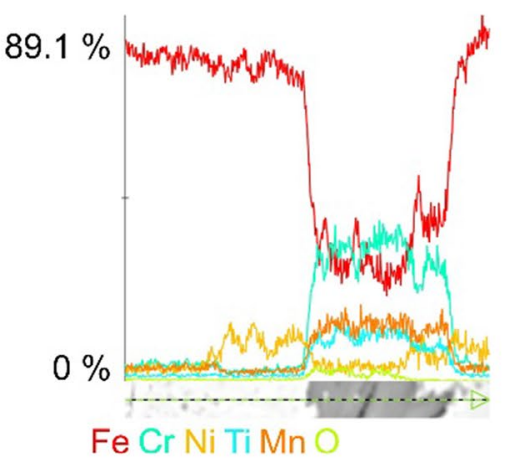

(c)

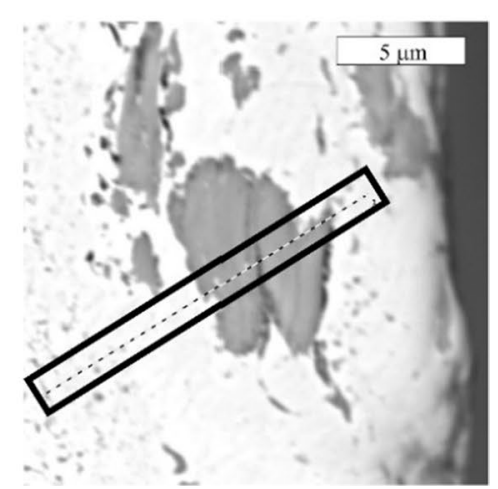

Fig. 8 Microscopic area (a) and an EDS linear distribution of elements (b) on the longitudinal section of the die along the line shown in Figure (c) in the area of the forging, with material sticking observed in area no. I in die W2 
Fig. 10 Material microstructure on the die's longitudinal section in area no. II: (a) W360, $0.1 \mathrm{~mm}, 1$ forging (W1), (b) W360, $0.2 \mathrm{~mm}, 1830$ forgings (W3), LM, etched

Fig. 11 SEM images obtained in area no. II: (a, b) W360, $0.1 \mathrm{~mm}$, first forging (W1), (c), d) $\mathrm{W} 360,0.2 \mathrm{~mm}, 1830$ forgings (W3)

Fig. 12 Material microstructure on the die's longitudinal section in area no. II: (a) QRO90, $0.1 \mathrm{~mm}, 1260$ forgings (W2), (b) QRO90, $0.2 \mathrm{~mm}, 2600$ forgings (W4) LM, etched (a)

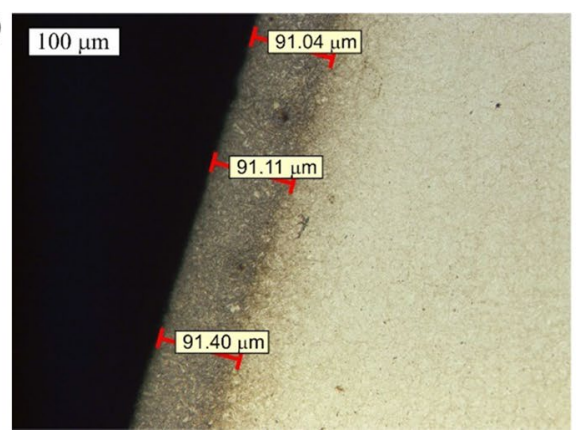

(a)

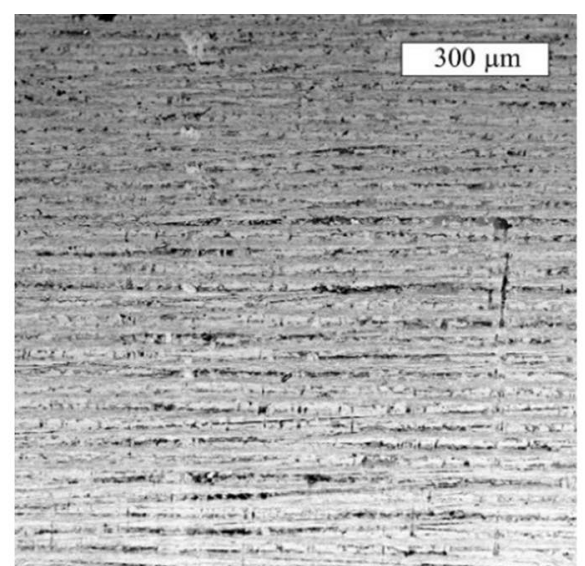

(c)

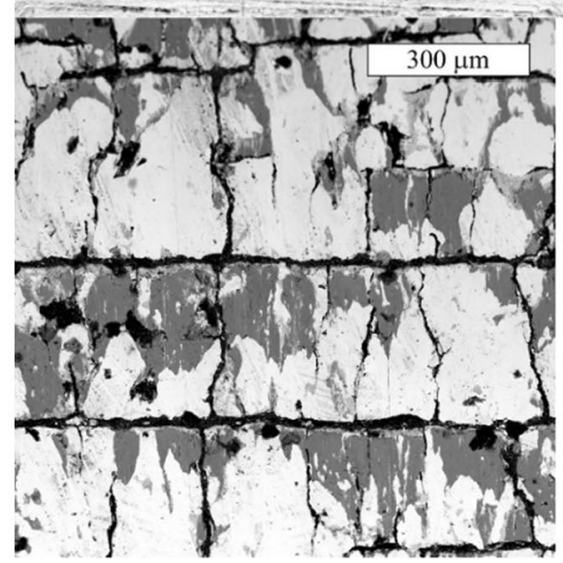

(a)

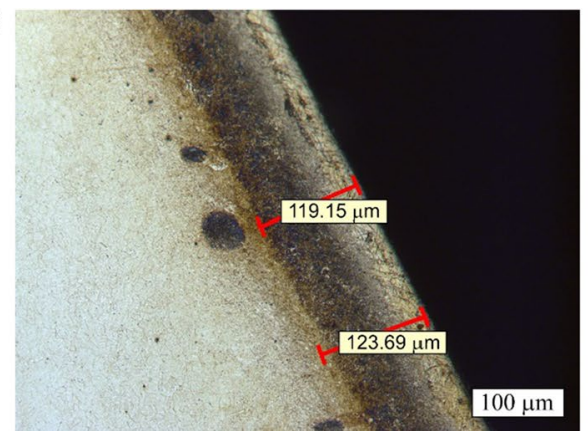

(b)

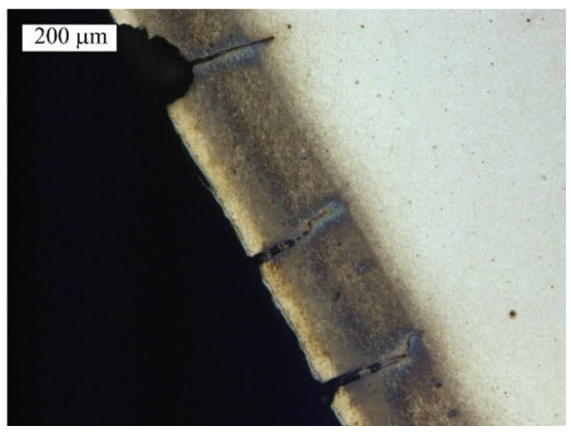

(b)

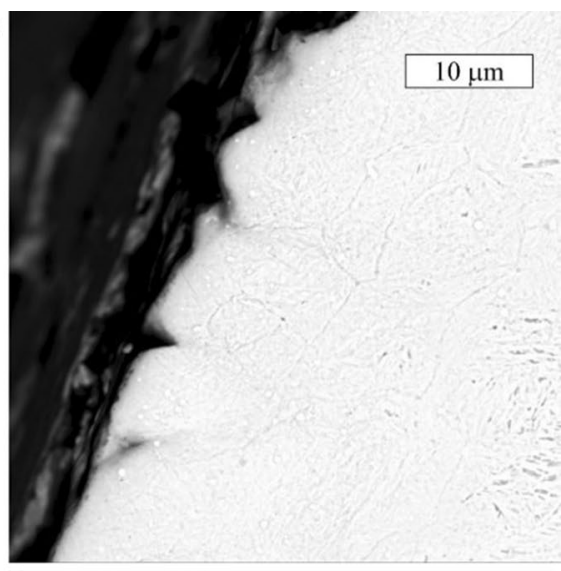

(d)

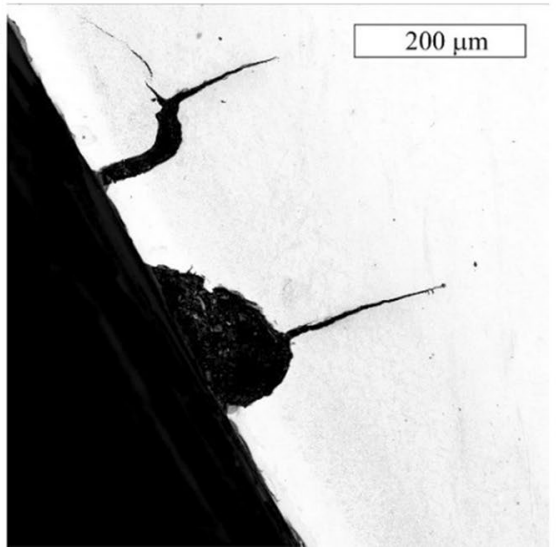

(b)

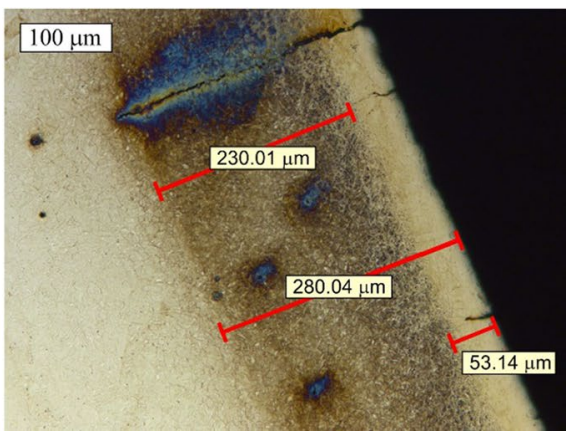


Fig. 13 SEM images obtained for the tool's area no. II: $(\mathbf{a}, \mathbf{b})$ QRO90, $0.1 \mathrm{~mm}, 1260$ forgings (W2) (c, d) QRO90, $0.2 \mathrm{~mm}$, 2600 forgings (W4) (a)

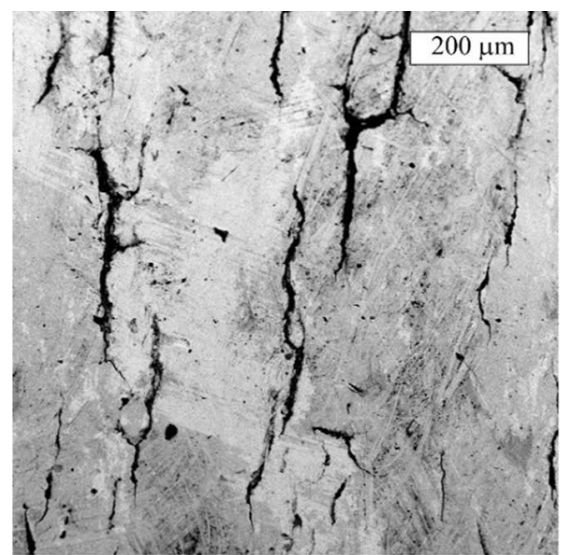

(c)

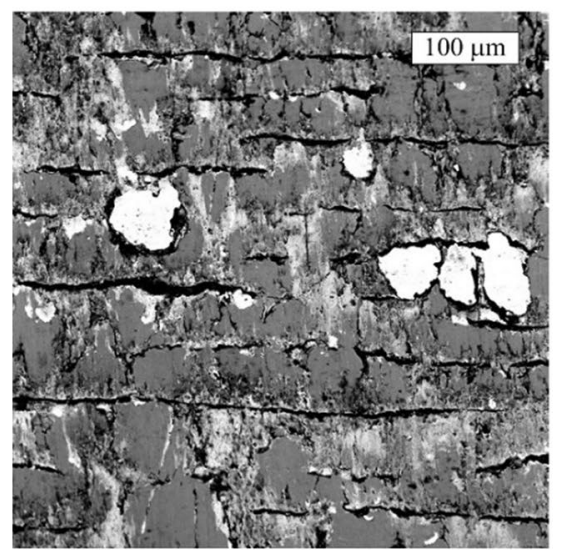

(b)

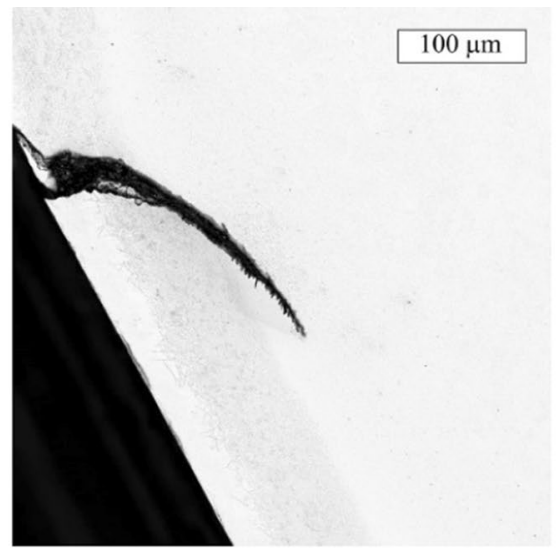

(d)

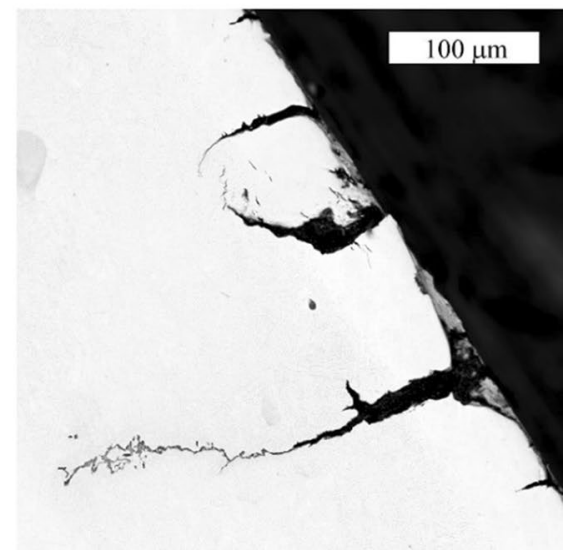

a spacing in the surface area, which lowered the thermal tensile stresses, and next developed into the material. Their presence favoured the formation of material loss in the tool (Figs. 10b, 11d).

In the case of dies W2 and W4, decomposition of the nitrided layer was observed, which revealed itself as the formation of a light-coloured area in the surface layer accompanied by lowering of hardness observed in this area at the further stage of the tests. Both dies (W2 and W4) were characterized by the presence of cracks; however, in the case of tool W2, their character was irregular, although they were arranged parallel to the die axis (Fig. 13a,b).

The character of the formed cracks in this area of dies with a higher thickness of the nitrided layer was similar for both steel grades (inserts W3 and W4). In the longitudinal section of insert W4, we can observe characteristic discontinuities, whose character suggest that they penetrated the material forming a network of cracks. In the area of the presence of these discontinuities, changes in colour were observed on the microsection, which point to the occurrence of oxidation in the areas of the forming cracks (Fig. 12b, 13d). In area no. II of tool W4, changes on the surface were observed, which pointed to rubbing off of the die material or its fragments being knocked into the surface (Fig. 13c). For this reason, an EDS surface distribution of elements in this area was conducted by means of an EDS analyser (Fig. 14). In the dark areas observed in the SEM microscopic image, an increased content of oxygen as well as chromium, vanadium and titanium was identified. These elements are present in the chemical composition of the charge material, which points to them originating from this material. It should, however, be noted that nickel, which is the main component of the charge material, was mainly localized in the lightcoloured areas. Next to it, there is a high content of iron and manganese, typical of the tool material. It is not very probable that nickel also comes from the tool material, as its content is too low to cause such a clear increase of its content in the element distribution. This suggests then that the charge material deposits ("sticks") on the tool material in the form of a very thin layer, whereas the remaining area is constituted by oxides coming from the scale, rubbed into the surface, analogical to those identified in area no. I. The deposition of oxides on the tool surface is connected with their high hardness (even at elevate temperatures) and the mixing of the oxides and the charge material (which was discussed earlier-Figs. 8 and 9). This will favour the knocking of the oxides into the tool surface. At the same time, the deformed forging material with a lower plastic resistance (resulting from heating and friction as well as 
Fig. 14 EDS surface distribution of elements obtained from the working surface of die W4 in zone no. II, SEM/EDX
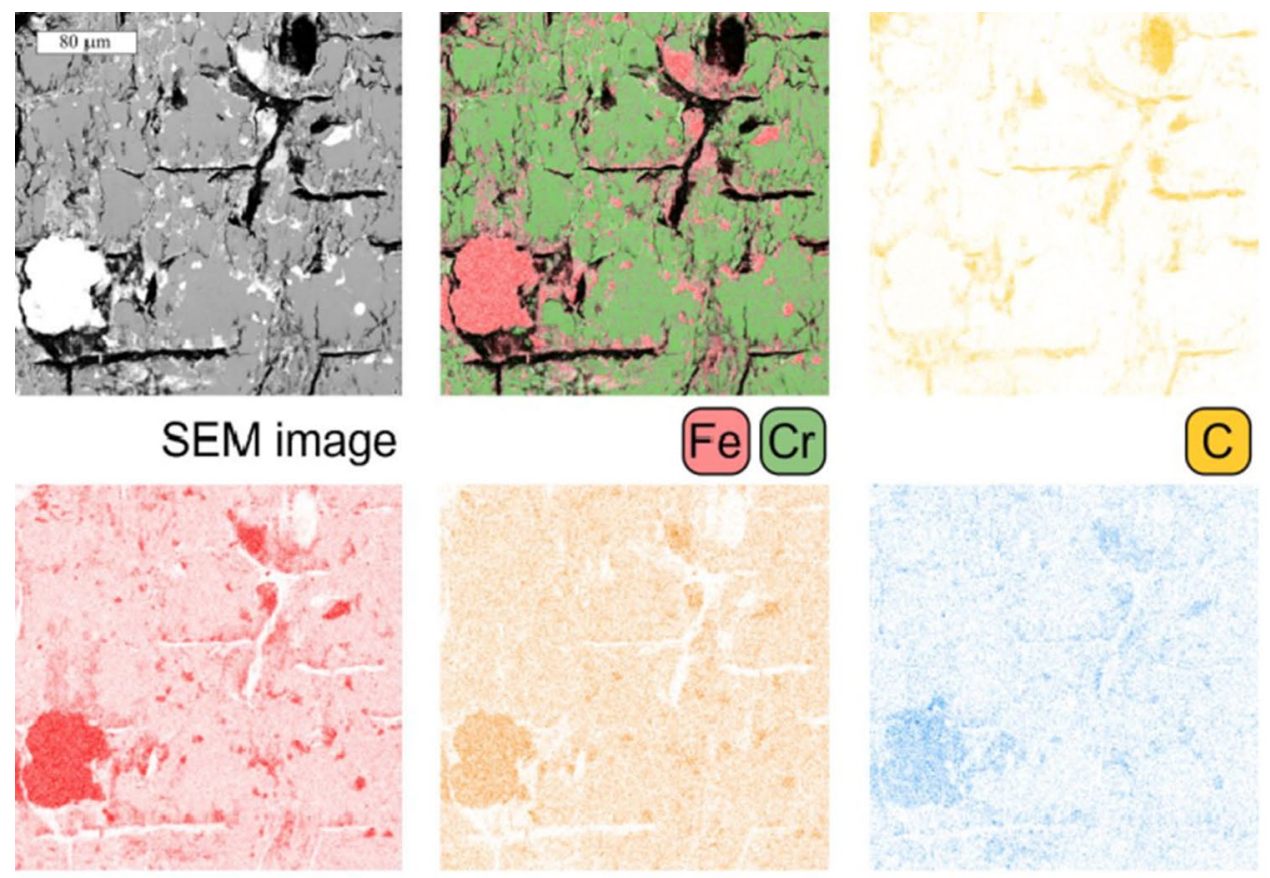

$\mathrm{Fe}$

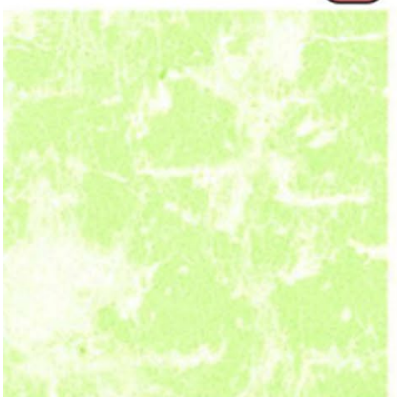

(0)

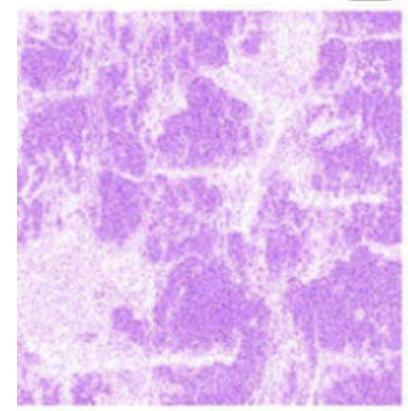

$\mathrm{Ti}$

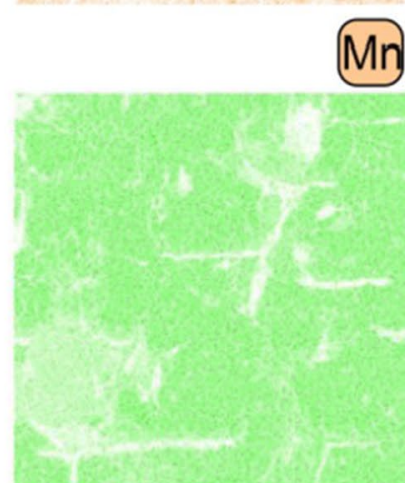

$\mathrm{Mn}$

$\mathrm{Ni}$

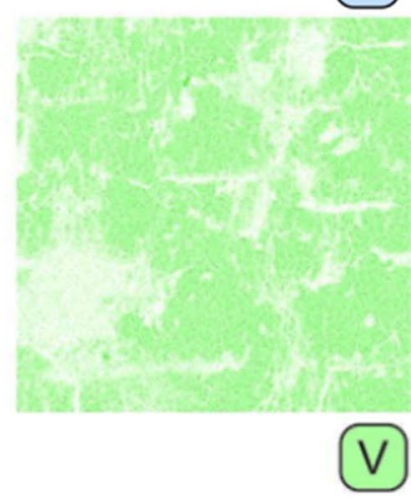

Cr

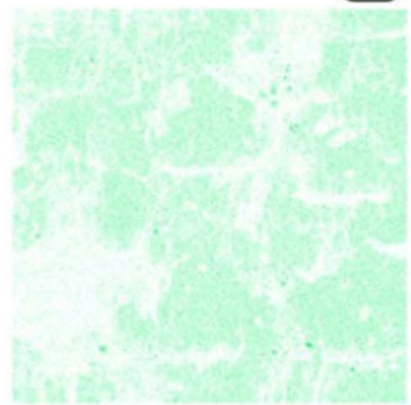

Al heat generation as a result of deformation work exchange) relatively deeply moves within the tool's working area.

Figure 15 shows the microscopic images obtained with low magnification on the longitudinal sections of the dies in the narrowing area, in zone no. III. In the case of insert $\mathrm{W} 1$, no significant changes in the nitrided layer thickness were observed in this area, which should be related to the fact that the tool underwent damage after first forging. For tools W2 and W3, total rubbing off of the nitrided layer is visible, which leads to local exposure of the native material. In turn, no rubbing was recorded in the case of die W4. However, it should be pointed out that, in the scan image shown in Fig. 3, die W4 in this area exhibited a non-uniform character of changes. 

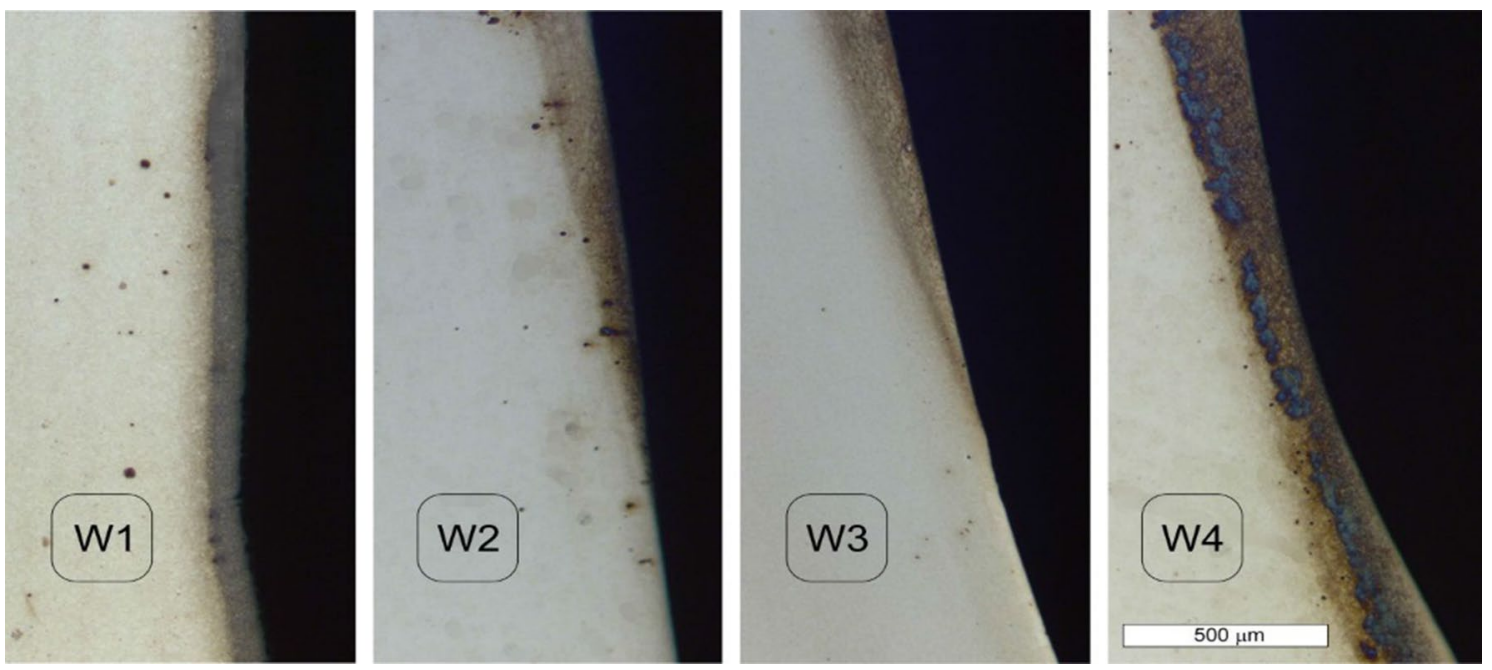

Fig. 15 Macrostructure of the die's longitudinal section in the area of the largest material loss in zone no. III. Nitrided layer visible at the surface

For all the tool groups, the most diversified character of wear is in the case of area no. III (Figs. 16, 17, 18, 19). In the case of tools with a lower layer thickness (W1, W2), no significant changes in this area were observed (16a,18a).

The surface changes referred mainly to the formation of single cracks developing perpendicular to the surface (Fig. 19b). In the area with a higher thickness of the nitrided layer, a crack network developing from area no. II was observed $(17 \mathrm{c}, 19 \mathrm{c})$. The cracks forming in this area were radial (Figs. 16b, 19b). In the areas with a higher nitrided layer thickness, extensive cracks were accompanied by micrometric-sized cracks, which did not form a spacing yet. The character of the forming cracks suggests that they could have been initiated on the grain boundaries, and all the more that, in the grain boundary area, their oxidation was observed, which favoured material decohesion (Figs. 17d, 19d).

The presented analysis of the wear of die working surfaces points to the fact that area no. III for tools with a nitrided layer $0.1 \mathrm{~mm}$ exhibited small traces of wear, whereas tools with a nitrided layer $0.2 \mathrm{~mm}$ in this area demonstrated an extensive network of fatigue cracks. In turn, area no. II is characterized by a crack network and decomposition of the nitrided layer for tools W2, W3 and W4. For all the tools, the key area is zone no. I, in which we observe abrasive wear as well as sticking of the forging material together with numerous traces of damage of the tool surface layer, which determines the tool's removal from further operation. Especially for tool W1, this area is critical because, as a result of insufficient material heating and incomplete dissolution of the hard metallic phases, the plastic resistance increases during deformation, which causes numerous rubs and blocking of the first forging in the smallest section of the tool (area no.I), and this, in consequence, leads to the die being removed from further production.

\subsection{Results of hardness measurements}

Figure 20 presents the results of hardness measurements performed on the representative tools. The measurements were carried out in zones marked in Fig. 2. In the analysis of the hardness measurement results (except for tools from group
Fig. 16 Material microstructure on the die's longitudinal section in area no. III: (a) W360, $0.1 \mathrm{~mm}, 1$ forging (W1), (b) W360, $0.2 \mathrm{~mm}, 1830$ forgings (W3). LM, etched (a)

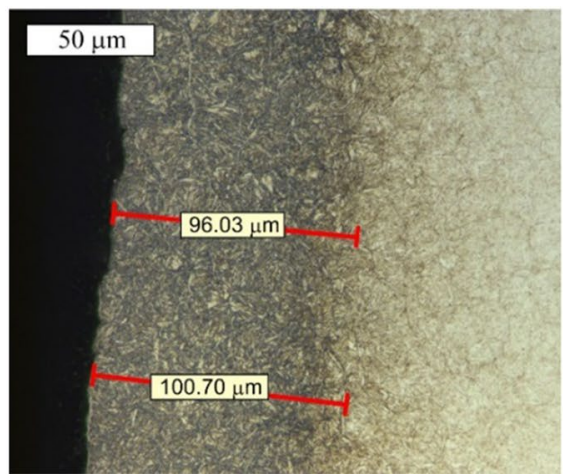

(b)

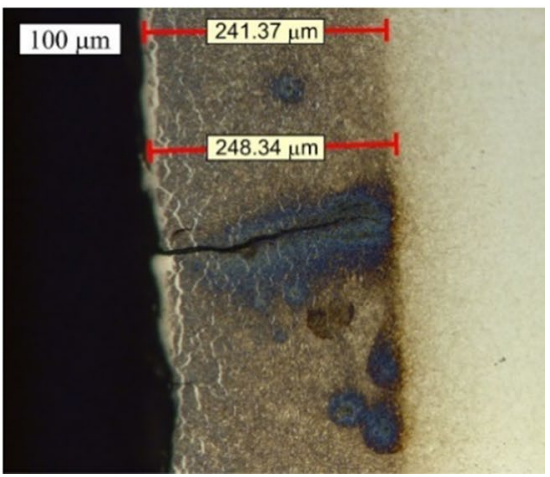


Fig. 17 SEM images for tool area no. III: (a, b) W360, $0.1 \mathrm{~mm}, 1$ forging (W1), (c, d) W360, $0.2 \mathrm{~mm}, 1830$ forgings (W3)

Fig. 18 Material microstructure on the die's longitudinal section in area no. III: (a) QRO90, $0.1 \mathrm{~mm}, 1260$ forgings (W2), (b) QRO90, $0.2 \mathrm{~mm}, 2600$ forgings (W4). LM, etched (a)

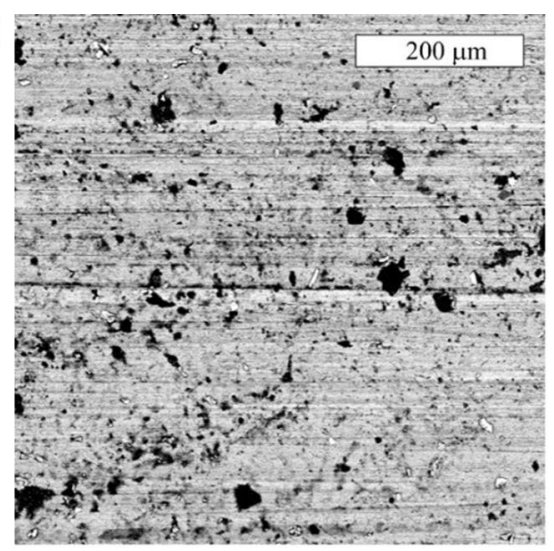

(c)

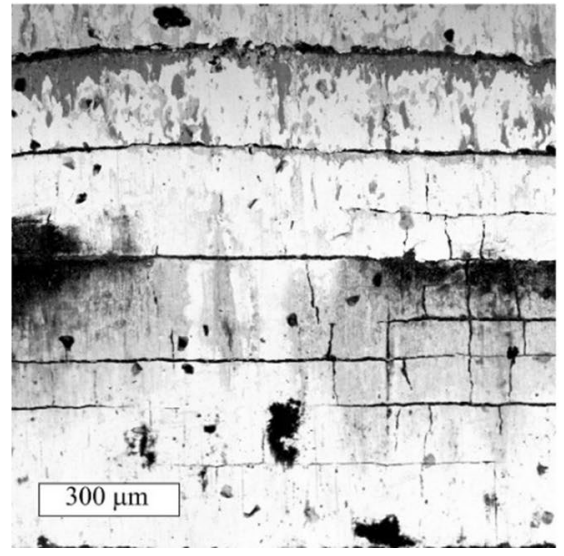

(a)

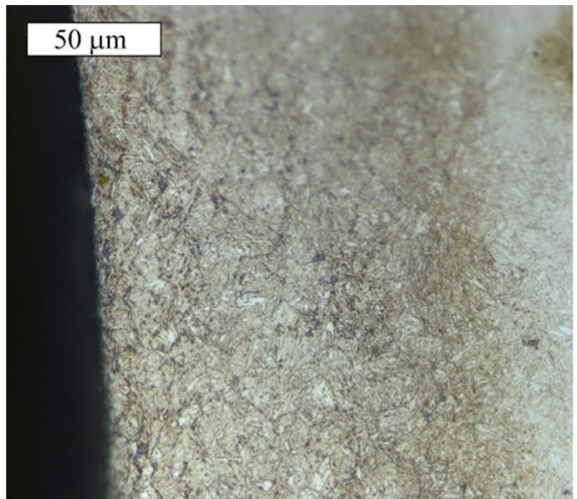

(b)

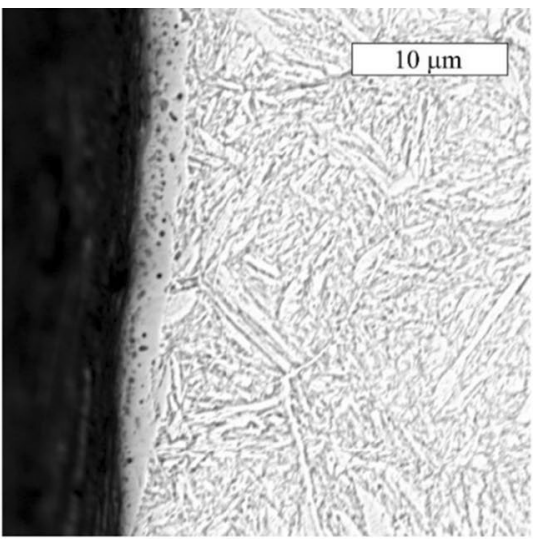

(d)

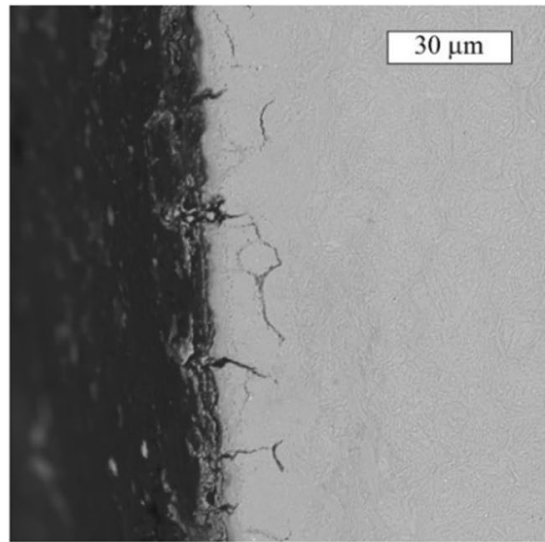

(b)

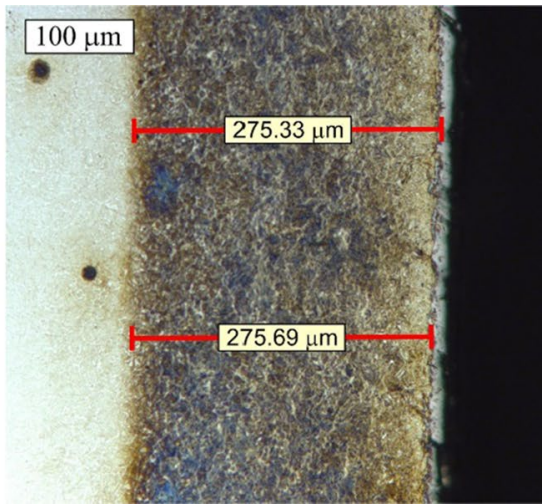

$\mathrm{W} 1$, which were removed from production as a result of blocking of the first forging), we can notice that, in the areas where the nitrided layer has been preserved, the hardness values are higher than the hardness of the core: $700 \mathrm{HV}$ for tools made of W360 and $600 \mathrm{HV}$ for tools made of QRO90. In turn, for the tool areas where the layer had undergone damage, the material hardness slightly dropped, similarly to those areas where it had remained-a hardness drop as a result of local material tempering.

However, for all the tools, it can be seen that the hardness values in the same areas are different, which points to the fact that the two applied tool materials (with different core hardness values) and the nitrided layer thicknesses have an effect on producing different maximal number of forgings. For the tool which has been removed after first forging, we can see a clear drop of hardness to the level of $400 \mathrm{HV}$, which is the hardness of the forging material stuck in this area. This is due to the fact that in zone no. I (forging arm forming) the forging material is unevenly stuck on the tool. In addition, by analysing the course of the hardness curve, it can be seen that it is "sharp" and corresponds to the transition from the hardness of the forging material to the hardness of the nitrided layer on the tool. On the other hand, in zone no. II and no. III, no sticking of 
(a)

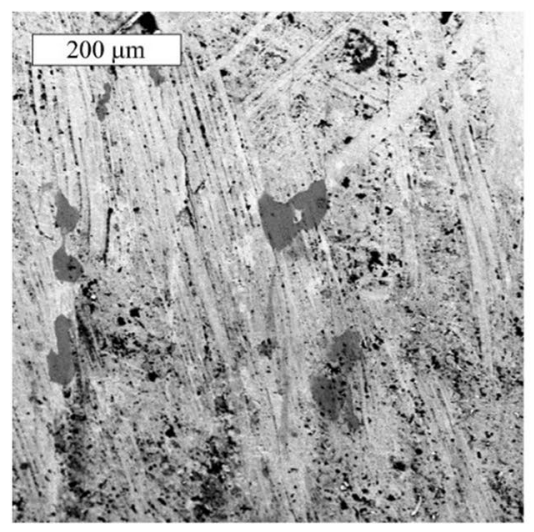

(c)

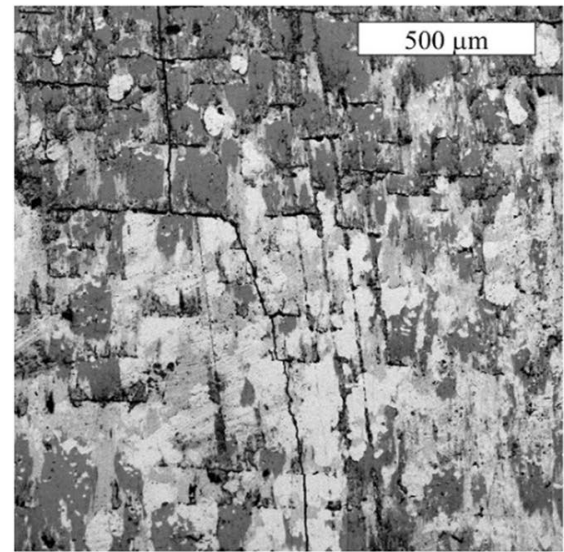

(b)

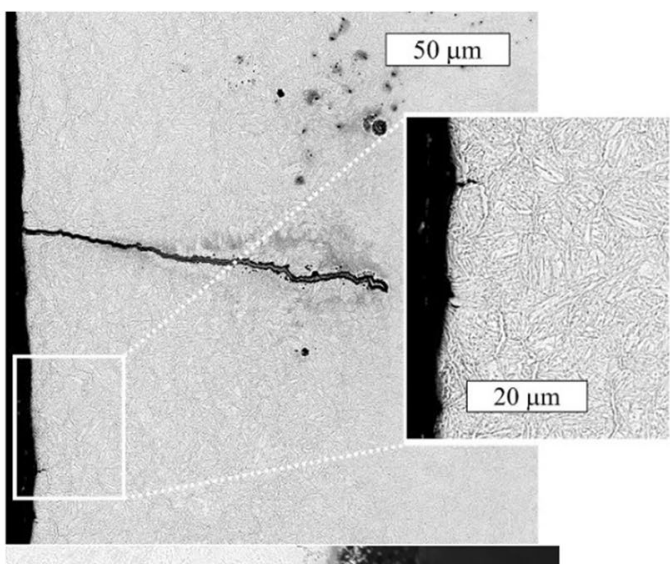

(d)

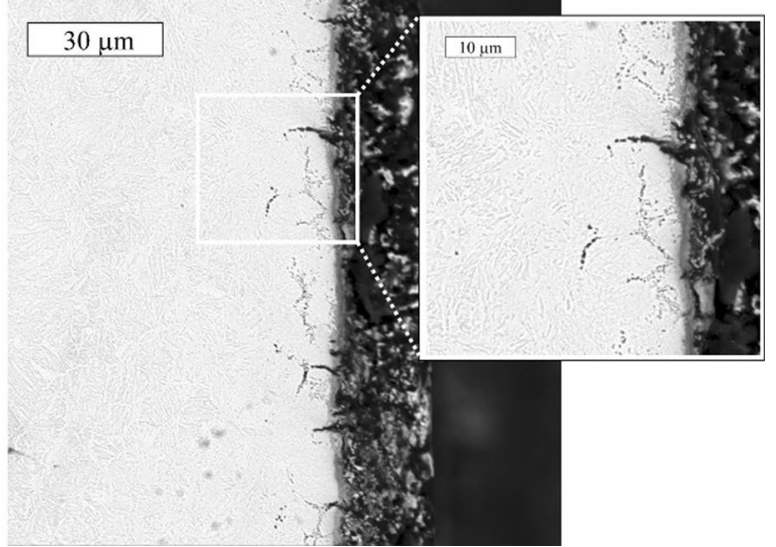

Fig. 19 SEM images for area no. III in the tool: (a, b) QRO90, $0.1 \mathrm{~mm}, 1260$ forgings (W2), (c, d) QRO90, $0.2 \mathrm{~mm}, 2600$ forgings (W4)
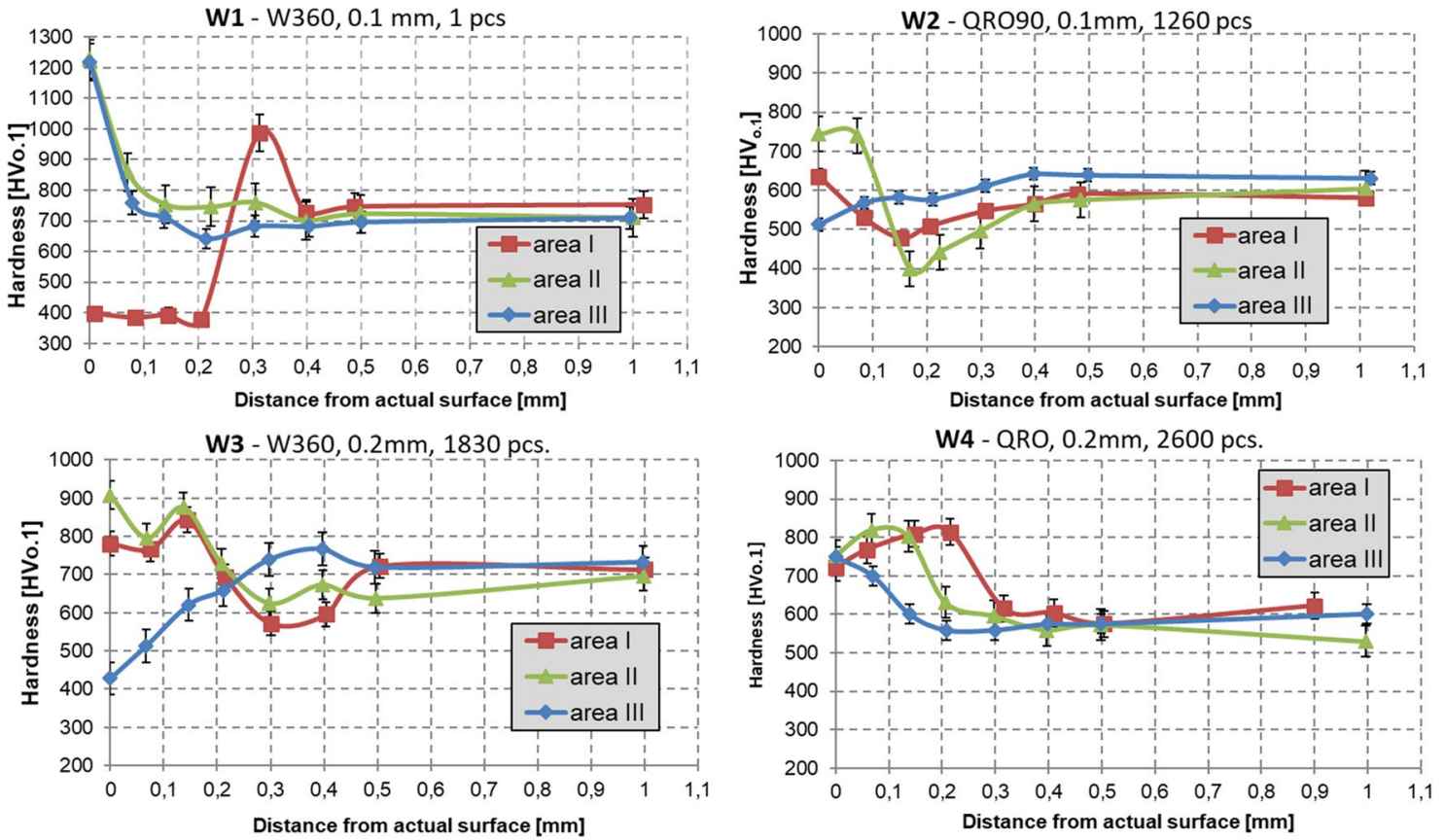

Fig. 20 Hardness measurement results for representative tools 
the forging material has occurred, so the hardness is at the level of the nitrided layer. In turn, for tools W2, W3 and W4, for which surface decomposition of the nitrided layer took place, we can observe a drop of hardness in area no. I and II, which is very distinct for the tool with a smaller nitrided layer thickness. The lower hardness in area no. 3 for tools W2 and W3 points to lack of nitrided layer in the analysed area (Fig. 15) and the occurrence of transformations connected with steel tempering (thermal softening), which, for material W360, reaches lower values.

\section{Conclusion}

The performed complex studies referring to the durability of dies used in the first (Ist) operation of extruding valve forgings prove that the thickness of the nitrided layer has a significant effect on the tool wear, while a slightly lower effect is exhibited by the type of the tool material. For the dies with nitrided layer thickness at the level of $0.2 \mathrm{~mm}$, twice as high durability was obtained, which equalled 2600 forgings, referring to the durability at the level of 1260 items for dies with the nitrided layer thickness $0.1 \mathrm{~mm}$, for the same material, QRO90. In turn, in the case of material W360, the low thickness of the nitrided layer as well as the low plastic deformability caused by high hardness of the material (56HRC) led to rubbing and blocking of the forging already at the beginning of the process. For a higher nitrided layer thickness $(0.2 \mathrm{~mm})$, in the case of material W360, it was possible to obtain the mean durability at the level of 1800 forgings. The critical area determining the tool's removal from further operation is area no. I, in the case of each tool. For all the tools except for W1, decomposition of the nitrided layer in areas no. I and II was observed, which is affected by the working time of the tools and the high tool temperature, above $600{ }^{\circ} \mathrm{C}$. The presence of a thicker nitrided layer on the tool enables operation in the presence of significant fatigue cracks, increasing its durability, which was observed both for the tool made of material W360, which produced 1800 items, and material QRO90, which worked over 2600 items. The tool material used, which is differentiated by carbon content and other alloying elements (V, Mo, Cr), affects durability and wear for area no. III. For steel QRO90, a higher stability of hardness was observed, which should be connected with the presence in its chemical composition of a higher content of elements forming simple carbides, with higher durability and higher affinity to carbon than chromium. Further research is planned aiming at an additional analysis of the nitrided layer thickness for other tool materials.

\section{Declarations}

Ethical approval This article does not contain any studies with human participants or animals performed by any of the authors.

Open Access This article is licensed under a Creative Commons Attribution 4.0 International License, which permits use, sharing, adaptation, distribution and reproduction in any medium or format, as long as you give appropriate credit to the original author(s) and the source, provide a link to the Creative Commons licence, and indicate if changes were made. The images or other third party material in this article are included in the article's Creative Commons licence, unless indicated otherwise in a credit line to the material. If material is not included in the article's Creative Commons licence and your intended use is not permitted by statutory regulation or exceeds the permitted use, you will need to obtain permission directly from the copyright holder. To view a copy of this licence, visit http://creativecommons.org/licenses/by/4.0/.

\section{References}

1. Forsberg P, Hollman P, Jacobson S. Wear mechanism study of exhaust valve system in modern heavy duty combustion engines. Wear. 2011;271(9-10):2477-84.

2. R. Elo, J. Heinrichs, S. Jacobson, Wear protective capacity of tribofilms formed on combustion engine valves with different surface textures, Wear 376-377 (2017) 1429-1436. PartB.

3. Priest M, Taylor CM. Automotive engine tribology—approaching the surface. Wear. 2011;241(2):53-65.

4. Wang YS, Narasimhan S, Larson JM, Schaefer SK. Wear and wear mechanism Simulation of heavy-duty engine intake valve and seat inserts. J Mater Eng Perform. 1998;7(1):53-65.

5. Yuanzhi Z, Zhimin Y, Jiangpin X. Microstructural mapping in closed die forging process of superalloy Nimonic $80 \mathrm{a}$ valve head. J Alloys Compounds. 2011;509(20):6106-12.

6. Lo KH, Shek CH, Lai JKL Recent developments in stainless steels, Mater Sci Eng R-Rep. 65 (2009) 39-104.

7. Calmunger M, Chai G, Eriksson R, Johansson S, Moverare JJ. Characterization of austenitic stainless steels deformed at elevated temperature, Metall. Metall Mater Trans A. 2017;48(10):4525-38.

8. Zhou J, Sun Z, Kanout'e P, Retraint D Effect of surface mechanical attrition treatment on low cycle fatigue properties of an austenitic stainless steel, Int J Fatigue (2017); 103: 309-317.

9. Hawryluk M, Gronostajski Z, Kaszuba MD, Krawczyk JJ, Widomski P, Ziemba J, Zwierzchowski M, Janik M. Wear mechanisms analysis of dies used in the process of hot forging a valve made of high nickel steel. Arch Metall Mater. 2018;63(4):1963-74.

10. Semiatin SL, ASM Handbook, Volume 14A - Metalworking: Bulk Forming. ASM International, (2005; 2009)

11. Hawryluk M, Kaszuba MD, Gronostajski Z, Sadowski P. Systems of supervision and analysis of industrial forging processes. Eksploatacja i Niezawodność-Maintenance and Reliability. 2016;18:315-24.

12. Smolik A Hybrid surface treatment technology for increase of hot forging dies. Arch Metallurgy Materials (2012); 57(3):657-664.

13. Altan T, Ngaile G, Shen G Cold and Hot Forging: Fundamentals and Applications, ASM International, Ohio, 2005.

14. J. Smolik Hard protective layers on forging dies-development and applications, Coatings, 376 (2021) 11 (4).

15. Paschke H, Weber M, Braeuer G, Yilkiran T, Behrens BA, Brand H. Optimized plasma nitriding processes for efficient wear reduction of forging dies. Arch Civ Mech Eng. 2012;12:407-12. 
16. Uma Devi M, Chakraborty TK, Mohanty ON Wear behaviour of plasma nitrided tool steels. Surface Coatings Technol (1999); 116-119: 212-221.

17. Paschke H, Weber M, Kaestner P, Braeuer G. Influence of different plasma nitriding treatments on the wear and crack behavior of forging tools evaluated by Rockwell indentation and scratch tests. Surf Coat Technol. 2010;205:1465-9.

18. Castanhera ID, Diniz AE, Button ST. Effects of plasma nitriding and nitrocarburizing thermochemical treatment and surface texture on surface damage evolution of hot stamping punches. Int J Adv Manuf Technol. 2021;112(7-8):2341-58.

19. Chaus AS, Kuracina V, Moravcik R, Hazlinger M, Kusy M. Effect of gas and ion plasma nitriding on the structure and properties of forging die inserts. Met Sci Heat Treat. 2021;62(9-10):577-85.

20. Kucharska B, Michalski J, Wójcik G. Mechanical and microstructural aspects of C20-steel blades subjected to gas nitriding. Arch Civ Mech Eng. 2019;19:147-56.

21. Yilkiran T, Behrens BA, Paschke H, Weber M, Brand H. The potential of plasma deposition techniques in the application field of forging processes. Arch Civ Mech Eng. 2012;12:284-91.

22. Bombač D, Terčelj M, Peruš I, Fajfar P. The progress of degradation on the bearing surfaces of nitrided dies for aluminium hot extrusion with two different relative lengths of bearing surface. Wear. 2013;303:10-21.

23. Pham MK, Nguyen DN, Hoang AT. Influence of vanadium content on the microstructure and mechanical properties of high-manganese steel. Int J Mech Mech Eng. 2018;18:141-7.

24. Hawryluk M, Gronostajski Z, Kaszuba MD, Polak S, Widomski $\mathrm{P}$, Ziemba J, Smolik J. Application of selected surface engineering methods to improve the durability of tools used in precision forging. Int J Adv Manuf Technol. 2017;93:2183-200.

25. P. Kula, E. Wolowiec, et all., Non-steady state approach to the vacuum nitriding for tools, Vacuum, 88 (2013) 1-7.

26. Widomski P, Kaszuba M, Dobras D, Zindulka O Development of a method of increasing the wear resistance of forging dies in the aspect of tool material, thermo-chemical treatment and PVD coatings applied in a selected hot forging process, Wear, 477 (2021).

27. Chang YY, Amrutwar S, Effect of Plasma Nitriding Pretreatment on the Mechanical Properties of AlCrSiN-Coated Tool Steels, Materials, 12(5) (2019) Article Number: 795.

28. A.E. Zeghin, M.S.J. Hashmi The effect of coating and nitriding on the wear behaviour of tool steels, J Materials Process Technol (2004) 155-156: 1918-1922.
29. Basso RLO, Pastore HO, Schmidt V, et al. Microstructure and corrosion behaviour of pulsed plasma-nitrided AISI H13 tool steel. Corros Sci. 2010;52(9):3133-9.

30. Yan MF, Chen BF, Li B. Microstructure and mechanical properties from an attractive combination of plasma nitriding and secondary hardening of M50 steel. Appl Surf Sci. 2018;455:1-7.

31. Bhadraiah D, Nouveau C, Veeraswami B, Ram Mohan Rao K (2021) Plasma based nitriding of tool steel for the enhancement of hardness. Materials Today Proc 46(1): 940-943.

32. Hawryluk $M$ et al. Support possibilities for 3D scanning of forging tools with deep and slim impressions for an evaluation of wear by means of replication methods, Materials 13 (8) (2020) Article Number: 1881.

33. Dworzak $€$, Hawryluk M, Janik M The impact of the lubricant dose on the reduction of wear dies used in the forging process of the valve forging, Materials, 14 (1) (2021) Article Number 212.

34. Krawczyk J, Widomski P, Kaszuba M Advanced complex analysis of the thermal softening of nitrided layers in tools during hot die forging, Materials, 14 (2) (2021) Article Number: 355.

35. Castro G, Fernández-Vicente A, Cid J. Influence of the nitriding time in the wear behaviour of an AISI H13 steel during a crankshaft forging process. Wear. 2007;263:1375-85.

36. Walkowicz J, Smolik J, Tacikowski J. Optimization of nitrided case structure in composite layers created by duplex treatment on the basis of PVD coating adhesion measurement. Surf Coat Technol. 1999;116-119:370-9.

37. Hubicki R, Richert M, Wiewióra M An experimental study of temperature effect on properties of nitride layers on X37CrMoV51 tool steel used in extrusion aluminium industry, Materials (2019) 13 (10) Article Number: 2311

38. Djellal R, Saker A, Bouzabata B, Mekki DE. Thermal stability and phase decomposition of nitrided layers on 316L and 310 austenitic stainless steels. Surf Coat Technol. 2017;325:533-8.

39. Summerville E, Venkatesan K. C, Subramanian Wear processes in hot forging press tools. Material Design. 1995;16(5):289-94.

40. Barrau O, Boher C, Gras R, Rezai-Aria F. Analysis of the friction and wear behaviour of hot work tool steel for forging. Wear. 2003;255:1444-54.

Publisher's Note Springer Nature remains neutral with regard to jurisdictional claims in published maps and institutional affiliations. 